Article

\title{
Functional Characterization of Individual- and Mixed-Burgundian Saccharomyces cerevisiae Isolates for Fermentation of Pinot Noir
}

\section{Emily Terrell ${ }^{1}$, Margaret A. Cliff ${ }^{2, *}$ and Hennie J. J. Van Vuuren ${ }^{1, *}$}

1 Wine Research Centre, Faculty of Land and Food Systems, University of British Columbia, Vancouver, BC V6T 1Z4, Canada; E-Mail: eterrel13@gmail.com

2 Pacific Agri-Food Research Centre, Agriculture and Agri-Food Canada, Summerland, BC V0H 1Z0, Canada

* Authors to whom correspondence should be addressed;

E-Mails: Margaret.Cliff@agr.gc.ca (M.A.C.); hjjvv@mail.ubc.ca (H.J.J.V.V.);

Tel.: +1-250-494-6365 (M.A.C.); Fax: +1-250-494-0755 (M.A.C.).

Academic Editors: Susan E. Ebeler and Helene Hopfer

Received: 8 January 2015 / Accepted: 9 March 2015 / Published: 19 March 2015

\begin{abstract}
Pinot noir has traditionally been fermented by native flora of multiple yeasts producing a complex combination of aromas and flavors. With the use of industrial dry yeasts, winemakers gained enological reliability and consistency in their wines, but lost diversity and complexity. This research evaluated the use of co-culturing yeasts to fulfill this dual role. Fermentations of Burgundian Saccharomyces cerevisiae isolates and their mixtures were evaluated for their enological characteristics and production of volatile compounds, at $22{ }^{\circ} \mathrm{C}$ and $27{ }^{\circ} \mathrm{C}$. The novel isolates were genetically unique and enologically equivalent to the industrial strains. Analysis of variance and principal component analysis of 25 headspace volatiles revealed differences among the yeasts and between the fermentation temperatures. Wines from the mixed-Burgundian isolates were most similar to one another and could be differentiated from the industrial strains at both $22{ }^{\circ} \mathrm{C}$ and $27^{\circ} \mathrm{C}$. Mixed-Burgundian wines at both temperatures had higher concentrations of ethyl esters and acetate esters, compared to the industrial strains which had higher concentrations of higher alcohols at $27^{\circ} \mathrm{C}$ and higher concentration of other ethyl esters at $22{ }^{\circ} \mathrm{C}$. Given the unique profiles of the co-cultured wines, this research offers winemakers a strategy for producing wines with unique and more complex characters without the risk of spontaneous fermentations.
\end{abstract}


Keywords: wine; $S$. cerevisiae; fermentation; volatile compounds; novel yeast strains

\section{Introduction}

Pinot noir is well known as one of the most complex and revered red wine grape varietals. As Pinot noir's popularity grows, there is an increasing demand for fermentation products designed to promote varietal-specific aromas and flavors as well as the complexity that some wine aficionados believe has deteriorated with the widespread use of single commercial yeast starter cultures. Recent advances in wine biotechnology may provide the best of both worlds: yeast products that perform enologically yet produce premium Pinot noirs redolent of the finest Old World techniques.

This search for premium yeast products has gone in several directions: (i) some scientists have utilized modern biotechnology and developed genetically modified yeast strains [1], (ii) others have captured the beneficial aspects of traditional spontaneous fermentation using mixed strain fermentations [2-5] and (iii) yet others have worked with native yeasts, not necessarily in spontaneous or mixed cultures to improve the aroma/flavor of fermented foods [6]. In such cases, novel yeast products must not only possess unique genetic traits or provide exceptional complexity, but must also meet the wine yeast phenotypic expectations that have evolved over the past 50 years of wine research. These enological traits have been grouped into two classes in the literature; technological traits that influence the efficiency of the fermentation process and qualitative traits that affect the chemical composition and the sensory profile of the finished wine [7].

The fermentation properties of wine yeast strains represent one subset of technological traits. Desirable fermentation properties include rapid initiation of fermentation, low nitrogen requirements, high fermentation efficiency, high osmotic stress tolerance, growth at high and low temperatures, moderate biomass formation and high ethanol tolerance [8]. Additional technological traits beyond fermentation properties are also desirable in wine yeast strains, including genetic stability, capacity for genetic marking, killer phenotype, low foam production, flocculation, high sulfur dioxide tolerance, low sulfur dioxide binding, compact sediment formation and resistance to desiccation and proteolytic activity [8].

Qualitative wine yeast traits directly affect the aroma or flavor of the finished wine. This encompasses the synthesis and liberation of a number of compounds, including acetaldehyde, acetic acid, sulfur compounds, higher alcohols and esters [8,9]. These compounds are currently understood to varying degrees in terms of their synthetic pathways, desirable concentrations, sensory impact and influence on other volatiles.

Despite the popularity of Pinot noir, research has not been particularly successful in elucidating the key aromatic compounds responsible for its varietal profile. Moio and Etievant [10] identified ethyl anthranilate, ethyl cinnamate, ethyl 2,3-dihydrocinnamate and methyl anthranilate as important Pinot noir odourants, although subsequent quantification of these compounds in 33 Pinot noir wines by Aubry et al. [11] revealed very low average concentrations that did not exceed the known thresholds of ethyl cinnamate and methyl anthranilate in water [12]. Aside from these esters, ethyl and methyl vanillate, acetovanillone, 3-methylthio-1-propanol, 2-phenylethanol, benzyl alcohol and 3-methylbutanoic, 
hexanoic, octanoic, and decanoic acids have been identified as potentially important in Pinot noir wines [13]. However, the characteristic aroma of Pinot noir is due to the combination of compounds derived from the grape, produced from the microflora (yeast, bacteria) and synthesized from primary and secondary metabolites [14].

As the understanding of the yeast volatiles continue to advance, so will the development of premium fermentation products designed to capture the benefits of improved flavor or flavor complexity from yeast fermentation. One such approach has been the investigation and characterization of mixed strain and mixed species inocula.

While the contribution of non-Saccharomyces yeast species to wine production has been the topic of much research [15], only a few studies have focused on the effects of deliberately mixing $S$. cerevisiae strains during fermentation [16]. By mixing yeast strains known to differ in their liberation of specific thiols, King et al. [16] were able to demonstrate that the volatile thiol content and the sensory profiles of wines differed in mixed $S$. cerevisiae culture beyond the effects of each individual yeast strain, suggesting a synergistic effect. Another study by Howell et al. [17] confirmed that the unique volatile profiles created by mixing $S$. cerevisiae strains during wine fermentation cannot be replicated by fermenting each strain individually and then blending the resulting wines. These findings, along with the simultaneous isolation of a number of novel $S$. cerevisiae strains from a premium vineyard in Burgundy led to the hypothesis that fermenting Pinot noir grape must with mixed ratios of these Burgundian isolates will result in unique volatile profiles that may be unique and/or more complex than those associated with fermentation by industrial or individual-Burgundian yeasts of $S$. cerevisiae.

To this end, research was undertaken: (i) to document the genetic uniqueness of the three new Burgundian isolates (A1, A2, A3) using genetic fingerprinting and phenotype characterization, (ii) to demonstrate that these isolates were enologically equivalent to industrial yeast strains for winemaking and (iii) to compare the volatile profiles of Pinot noir wines fermented individually and in mixtures to industrial strains fermented at $22^{\circ} \mathrm{C}$ and $27^{\circ} \mathrm{C}$.

\section{Results and Discussion}

\subsection{Genetic and Phenotypic Characterization of Wine Yeast Strains}

Genetic and phenotypic characterization revealed the genetic uniqueness of the Burgundian isolates (A1, A2, A3) and their compatibility with one another in mixed culture fermentations. PCR-based genetic fingerprinting [18] differentiated the three Bugundian isolates from six industrial (commercial) strains (Figure 1). All strains had unique banding patterns except Enoferm Burgundy (BGY) and Maurivin B (MB) which were identical. Therefore, MB was excluded from further analysis (Figure 1). As such, they were genetically different from one another and would be expected to have different enological characteristics [19].

The Burgundian isolates were identified as killer positive $(\mathrm{K}+)$ phenotype. As such they would be expected to kill wild yeast strains, predominate in individual strain fermentations and be able to be co-cultured with one another [20,21]. The initial strain ratios for each of the mixed cultures (M1, M2, M3, M4) at $22{ }^{\circ} \mathrm{C}$ and $27{ }^{\circ} \mathrm{C}$ are shown in Figure 2a,b. Colony PCR in conjunction with $\delta$ sequence typing revealed the strain ratios at the midpoint $\left(22{ }^{\circ} \mathrm{C}\right.$ Figure $2 \mathrm{c} ; 27{ }^{\circ} \mathrm{C}$ Figure $\left.2 \mathrm{~d}\right)$ and end $\left(22{ }^{\circ} \mathrm{C}\right.$ 
Figure 2e; $27{ }^{\circ} \mathrm{C}$ Figure $2 \mathrm{f}$ ) of fermentation. The mixed culture M2 approximately maintained the inoculated yeast ratios at the midpoint (Figure 2c,d) and immediately following fermentation (Figure $2 \mathrm{~d}$,e) at $22{ }^{\circ} \mathrm{C}$ and $27{ }^{\circ} \mathrm{C}$; whereas, the mixed culture $\mathrm{M} 3$ maintained the yeast ratios at $22{ }^{\circ} \mathrm{C}$, but not at $27^{\circ} \mathrm{C}$. In contrast, mixed cultures M1 and M4 did not maintain their inoculated yeast ratios at either $22{ }^{\circ} \mathrm{C}$ or $27^{\circ} \mathrm{C}$.

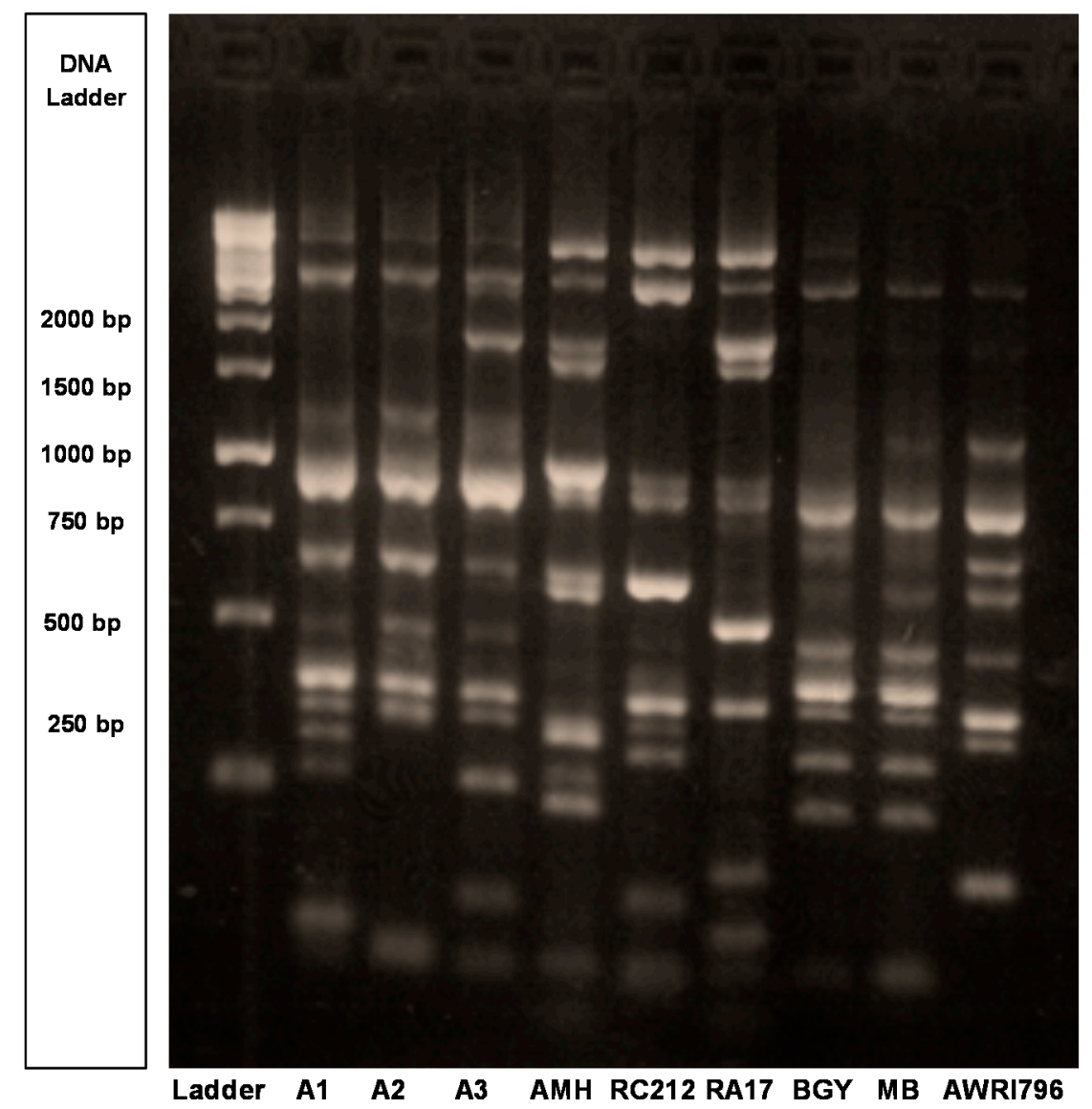

Figure 1. Genetic fingerprints of three Burgundian S. cerevisiae isolates (A1, A2, A3) and six industrial $S$. cerevisiae yeast strains [Enoferm Assmanshausen (AMH), Enoferm Burgundy (BGY), Lalvin RA17 (RA17), Lalvin Bourgorouge (RC212), Maurivin B (MB), Australian Wine Research Institute 796 (AWRI796)]. The $\delta$ sequence typing of all strains is shown relative to the 1 kilobase $(\mathrm{kb})$ DNA ladder obtained from Fermentas (Thermo Fisher, Burlington, ON, Canada). Since the genetic fingerprint and fermentation data for BGY and MB were identical, MB was excluded from further analysis.

Interestingly, strains A1, A2 and A3 were present in all mixtures fermented at $22{ }^{\circ} \mathrm{C}$ and $27{ }^{\circ} \mathrm{C}$, despite the tendency of strain A3 to exceed its inoculated ratio at the midpoint of the fermentation (Figure 2c,d). If a mixed-Burgundian yeast product were to be commercialized, the fermentation kinetics of the three isolates A1, A2 and A3 would need to be more thoroughly examined, both individually and in combination, in order to optimize performance. 

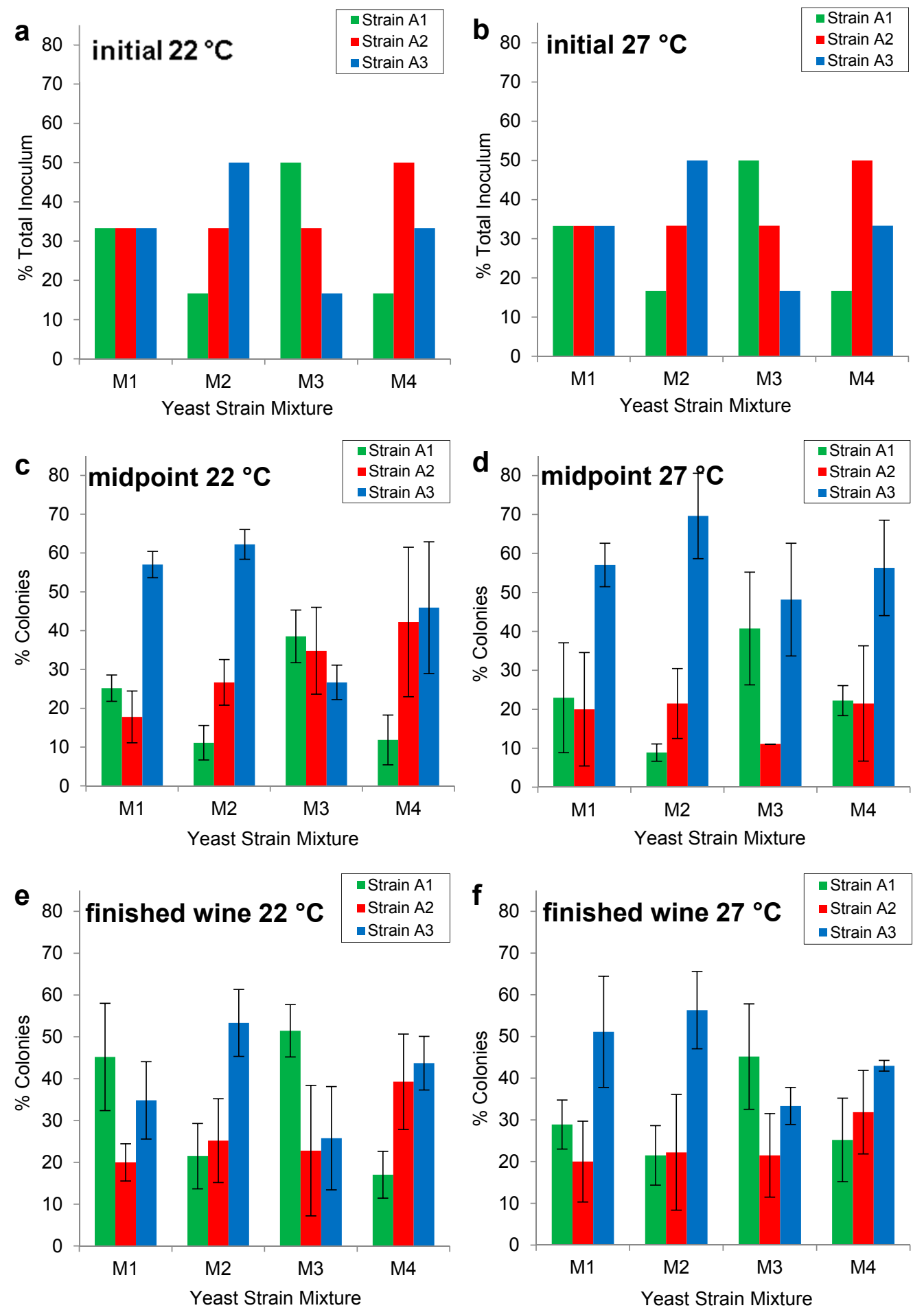

Figure 2. Initial inoculation ratios of Pinot noir fermentations co-cultured with Burgundian isolates (A1, A2, A3) in mixtures M1 (1:1:1), M2 (1:2:3), M3 (3:2:1), and M4 (1:3:2) at (a) $22{ }^{\circ} \mathrm{C}$ and (b) at $27{ }^{\circ} \mathrm{C}$. Mixed strain populations at the midpoint $(\sim 6.0 \% \mathrm{v} / \mathrm{v}$ ethanol) (c) at $22{ }^{\circ} \mathrm{C}$ and (d) $27{ }^{\circ} \mathrm{C}$ and end of fermentation $\left(\sim 13.5 \% \mathrm{v} / \mathrm{v}\right.$ ethanol) (e) at $22{ }^{\circ} \mathrm{C}$ and (f) at $27{ }^{\circ} \mathrm{C}$. Yeast populations were quantified using colony PCR in conjunction with $\delta$ sequence typing on 45 colonies for each of three biological replicates. 


\subsection{Enological Characterization of Wine Yeast Strains}

Analyses of variance (ANOVA) demonstrated that six of the eight enological characteristics varied significantly among the yeasts (Table 1). Two characteristics, ethanol and sugar/ethanol ratio, with values of $13.39 \%-13.77 \% \mathrm{v} / \mathrm{v}$ and $0.464-0.482$, respectively, were not different among the yeasts.

Glycerol production by the individual- and mixed-Burgundian isolates fell within the range $\left(8-10.5 \mathrm{~g} \cdot \mathrm{L}^{-1}\right)$ associated with industrial yeasts (Table 1); this demonstrated their enological equivalence and suitability for winemaking. Wines from A1 at $22{ }^{\circ} \mathrm{C}$, had a higher glycerol concentration than the other individual- and mixed-Burgundian wines (Table 1). Thus, this yeast would be looked upon favorably by winemakers, for glycerol increases osmotolerance and shunts carbon away from ethanol production [22].

In contrast, the individual- and mixed-Burgundian isolates produced amongst the lowest acetic acid concentrations, with the commercial strain BGY producing the highest concentrations at both $22{ }^{\circ} \mathrm{C}$ and $27^{\circ} \mathrm{C}$ (Table 1). However all concentrations were below the red wine aroma detection threshold $\left(0.6-0.9 \mathrm{~g} \cdot \mathrm{L}^{-1}\right)$ [23] and beneath the US legal limit of $1.2 \mathrm{~g} \cdot \mathrm{L}^{-1}$. Therefore, all isolates and their mixtures were acceptable for commercial winemaking.

Ethanol tolerance of all yeast strains was within a single percentage point of one another at $22{ }^{\circ} \mathrm{C}$ $(18.15 \%-18.90 \% \mathrm{v} / \mathrm{v})$ and $27{ }^{\circ} \mathrm{C}(17.35 \%-17.75 \% \mathrm{v} / \mathrm{v})$ (Table 1). Two industrial strains (AMH, BGY) were markedly less tolerant than the other yeast strains, producing 17.68 and $18.21 \%(\mathrm{v} / \mathrm{v})$ ethanol at $22{ }^{\circ} \mathrm{C}$, and 15.42 and $16.33 \%(\mathrm{v} / \mathrm{v})$ ethanol at $27{ }^{\circ} \mathrm{C}$, respectively. At both temperatures, the individualand mixed-Burgundian isolates had intermediate ethanol tolerances, reflecting that they were enologically similar to the industrial strains.

Final optical density (growth phenotype) of the yeasts revealed that the Burgundian isolate (A1), and its mixtures (M1-M4), showed aberrant overall growth pattern (Table 1), with a complete scattering of OD measurements upon reaching the stationary phase due to flocculation. Flocculation of yeast cells is considered desirable in winemaking [8] for it allows for easier exclusion of yeast sediment during racking [24]. This characteristic could be particularly important for the production of premium unfiltered red wines. In contrast, BGY had a visibly longer lag phase at $27{ }^{\circ} \mathrm{C}$; this was somewhat undesirable for it would allow other yeasts to establish and potentially dominate the fermentation. Interestingly, Enoferm Assmanshausen (AMH) reached only $75 \%$ of the final cell density of the other strains (Table 1), which were similar. Based on growth phenotype, the Burgundian isolates and their mixtures were considered enologically equivalent, as long as the late flocculation of strain A1 could be manageable in the cellar.

Foam production of the Burgundian isolates $\left(22{ }^{\circ} \mathrm{C}, 15.7-16.3 \mathrm{~mm} ; 27{ }^{\circ} \mathrm{C}, 20.3-32.3 \mathrm{~mm}\right)$ fell within the range produced by the industrial strains $\left(22{ }^{\circ} \mathrm{C}, 9.7-34.0 \mathrm{~mm} ; 27{ }^{\circ} \mathrm{C}, 7.3-28.0 \mathrm{~mm}\right)$ (Table 1), with the individual-Burgundian isolates (A1, A2) producing foam at the higher end of this range. While they did not differ significantly from two industrial strains (BGY, RC212), further investigations would be necessary to assess their foam production in other musts and to establish the necessary tank requirements [24]. 
Table 1. Mean ${ }^{\mathrm{a}, \mathrm{b}}$ enological characteristics (glycerol, acetic acid, ethanol tolerance, final optical density, foam height, sulfur dioxide) for Pinot noir fermented with industrial strains and individual- and mixed-Burgundian S. cerevisiae isolates, at $22{ }^{\circ} \mathrm{C}$ and $27{ }^{\circ} \mathrm{C}$. For each determination, strain and temperature effects are shown with subscripts and $p$ values, respectively.

\begin{tabular}{|c|c|c|c|c|c|c|c|c|c|c|}
\hline \multirow{2}{*}{\multicolumn{2}{|c|}{$\begin{array}{c}\text { Yeast } \\
\text { Strain or Isolate }\end{array}$}} & \multicolumn{2}{|c|}{ Glycerol $\left(g \cdot L^{-1}\right)$} & \multirow{2}{*}{$p^{\mathrm{c}}$} & \multicolumn{2}{|c|}{ Acetic Acid $\left(g \cdot L^{-1}\right)$} & \multirow{2}{*}{$p$} & \multicolumn{2}{|c|}{ Ethanol Tolerance $^{d}$} & \multirow{2}{*}{$p$} \\
\hline & & $22^{\circ} \mathrm{C}$ & $27^{\circ} \mathrm{C}$ & & $22^{\circ} \mathrm{C}$ & $27^{\circ} \mathrm{C}$ & & $22^{\circ} \mathrm{C}$ & $27^{\circ} \mathrm{C}$ & \\
\hline \multirow{5}{*}{ Industrial } & АМН & $8.79 \mathrm{~d}$ & $10.02 \mathrm{~d}$ & $* * *$ & $0.124 \mathrm{~b}$ & 0.187 cde & $* * *$ & $17.68 \mathrm{a}$ & $15.42 \mathrm{a}$ & $* * *$ \\
\hline & AWRI796 & $9.34 \mathrm{e}$ & $10.64 \mathrm{e}$ & $*$ & $0.132 \mathrm{c}$ & $0.179 \mathrm{bcd}$ & $*$ & $18.30 \mathrm{bc}$ & $17.66 \mathrm{ef}$ & $* *$ \\
\hline & BGY & $8.80 \mathrm{~d}$ & $9.65 \mathrm{bcd}$ & $* *$ & $0.337 \mathrm{j}$ & $0.411 \mathrm{~h}$ & $* *$ & $18.21 \mathrm{~b}$ & $16.32 \mathrm{~b}$ & $* * *$ \\
\hline & RA17 & $8.43 \mathrm{bc}$ & $9.31 \mathrm{ab}$ & $*$ & $0.224 \mathrm{~h}$ & $0.292 \mathrm{~g}$ & $* * *$ & $18.56 \mathrm{~cd}$ & $17.59 \mathrm{e}$ & $* * *$ \\
\hline & RC212 & $7.94 \mathrm{a}$ & $9.12 \mathrm{a}$ & $* *$ & $0.246 \mathrm{i}$ & $0.250 \mathrm{f}$ & ns & $18.90 \mathrm{e}$ & $17.58 \mathrm{e}$ & $* * *$ \\
\hline \multirow{3}{*}{$\begin{array}{l}\text { Individual } \\
\text { Burgundian }\end{array}$} & $\mathbf{A 1}$ & $8.49 \mathrm{bcd}$ & $9.25 \mathrm{a}$ & $* *$ & $0.119 \mathrm{a}$ & $0.142 \mathrm{a}$ & $* *$ & $18.20 \mathrm{~b}$ & $17.56 \mathrm{de}$ & $* * *$ \\
\hline & A2 & $9.19 \mathrm{e}$ & $9.63 \mathrm{bc}$ & $* *$ & $0.209 \mathrm{~g}$ & $0.240 \mathrm{f}$ & $*$ & $18.73 \mathrm{de}$ & $17.35 \mathrm{c}$ & $* * *$ \\
\hline & A3 & $8.44 \mathrm{bc}$ & $9.41 \mathrm{ab}$ & $* * *$ & $0.135 \mathrm{c}$ & $0.167 \mathrm{~b}$ & * & $18.15 \mathrm{~b}$ & $17.42 \mathrm{~cd}$ & $* * *$ \\
\hline \multirow{5}{*}{ Mixed Burgundian } & M1 (1:1:1) & $8.37 \mathrm{~b}$ & $9.33 \mathrm{ab}$ & $* * *$ & $0.147 \mathrm{~d}$ & 0.187 cde & $* *$ & $18.55 \mathrm{~cd}$ & $17.75 \mathrm{f}$ & $* * *$ \\
\hline & M2 (1:2:3) & $8.46 \mathrm{bc}$ & $9.85 \mathrm{~cd}$ & $* *$ & $0.160 \mathrm{e}$ & $0.194 \mathrm{de}$ & ns & $18.40 \mathrm{bc}$ & $17.64 \mathrm{ef}$ & $* * *$ \\
\hline & M3 (3:2:1) & $8.48 \mathrm{bcd}$ & $9.37 \mathrm{ab}$ & $* *$ & $0.149 \mathrm{~d}$ & $0.171 \mathrm{bc}$ & $* *$ & $18.57 \mathrm{~cd}$ & 17.72 ef & $* * *$ \\
\hline & M4 (1:3:2) & $8.72 \mathrm{~cd}$ & $9.65 \mathrm{bcd}$ & $* *$ & $0.177 \mathrm{f}$ & $0.200 \mathrm{e}$ & $* *$ & $18.50 \mathrm{~cd}$ & $17.75 \mathrm{f}$ & * \\
\hline & Range & $7.94-9.34$ & $9.12-10.64$ & & $0.119-0.337$ & $0.142-0.411$ & & $17.68-18.73$ & $15.42-17.75$ & \\
\hline \multirow{2}{*}{\multicolumn{2}{|c|}{$\begin{array}{c}\text { Yeast } \\
\text { Strain or Isolate }\end{array}$}} & \multicolumn{2}{|c|}{ Final Optical Density $^{\text {e }}$} & & \multicolumn{2}{|c|}{ Foam Height ${ }^{\mathrm{f}}(\mathrm{mm})$} & & \multicolumn{2}{|c|}{ Sulfur Dioxide ${ }^{\mathrm{f}}\left(\mathrm{mg} \cdot \mathrm{L}^{-1}\right)$} & \\
\hline & & $22^{\circ} \mathrm{C}$ & $27^{\circ} \mathrm{C}$ & $p$ & $22^{\circ} \mathrm{C}$ & $27^{\circ} \mathrm{C}$ & $p$ & $22^{\circ} \mathrm{C}$ & $27^{\circ} \mathrm{C}$ & $\boldsymbol{p}$ \\
\hline \multirow{5}{*}{ Industrial } & АМH & $1.494 \mathrm{a}$ & $1.667 \mathrm{a}$ & $* *$ & $9.7 \mathrm{a}$ & $7.3 \mathrm{a}$ & ns & $15.0 \mathrm{ab}$ & $12.5 \mathrm{ab}$ & ns \\
\hline & AWRI796 & $1.938 \mathrm{~d}$ & $1.914 \mathrm{bc}$ & ns & $10.0 \mathrm{a}$ & $18.0 \mathrm{~b}$ & * & $9.2 \mathrm{a}$ & $12.1 \mathrm{ab}$ & ns \\
\hline & BGY & $1.658 \mathrm{~b}$ & $1.841 \mathrm{~b}$ & ns & $34.0 \mathrm{~b}$ & $28.0 \mathrm{de}$ & ns & $9.9 \mathrm{a}$ & $6.4 \mathrm{a}$ & ns \\
\hline & RA17 & $1.931 \mathrm{~d}$ & $1.992 \mathrm{c}$ & $* * *$ & $13.3 \mathrm{a}$ & $20.3 \mathrm{bc}$ & $* *$ & $24.8 \mathrm{c}$ & $50.3 \mathrm{f}$ & $* *$ \\
\hline & RC212 & $1.940 \mathrm{~d}$ & $1.989 \mathrm{c}$ & $*$ & $16.3 \mathrm{a}$ & $24.0 \mathrm{~cd}$ & ns & $36.5 \mathrm{~d}$ & $28.4 \mathrm{~cd}$ & $\mathrm{~ns}$ \\
\hline \multirow{3}{*}{$\begin{array}{l}\text { Individual } \\
\text { Burgundian }\end{array}$} & A1 & $\mathrm{n} / \mathrm{a}$ & $\mathrm{n} / \mathrm{a}$ & & $16.0 \mathrm{a}$ & $28.3 \mathrm{de}$ & ns & $26.1 \mathrm{c}$ & 40.9 ef & $* * *$ \\
\hline & $\mathbf{A 2}$ & $1.819 \mathrm{c}$ & $1.831 \mathrm{~b}$ & ns & $15.7 \mathrm{a}$ & $32.3 \mathrm{e}$ & $* * *$ & $32.6 \mathrm{~d}$ & $30.4 \mathrm{de}$ & $\mathrm{ns}$ \\
\hline & A3 & $1.861 \mathrm{~cd}$ & $1.979 \mathrm{c}$ & $* *$ & $16.3 \mathrm{a}$ & $20.3 \mathrm{bc}$ & ns & $20.6 \mathrm{bc}$ & $18.2 \mathrm{bc}$ & $\mathrm{ns}$ \\
\hline \multirow[t]{2}{*}{ Mixed Burgundian } & M1-M4 & $\mathrm{n} / \mathrm{a}$ & $\mathrm{n} / \mathrm{a}$ & & $\mathrm{n} / \mathrm{a}$ & $\mathrm{n} / \mathrm{a}$ & & $\mathrm{n} / \mathrm{a}$ & $\mathrm{n} / \mathrm{a}$ & \\
\hline & Range & $1.494-1.938$ & $1.667-1.992$ & & $9.7-34.0$ & $7.3-32.3$ & & $9.2-36.5$ & $6.4-50.3$ & \\
\hline
\end{tabular}

${ }^{\mathrm{a}}$ The mean values of the biological replicates of each yeast strain were shown $(n=3) .{ }^{\mathrm{b}}$ Yeast strain means not sharing the same subscript are significantly $(p \leq 0.05)$ different at each temperature. ${ }^{\mathrm{c}} \mathrm{ns}, *, * *, * * *$ indicates non-significant and significant at $p \leq 0.05,0.01$ and 0.001 , respectively, for temperature effects. ${ }^{\mathrm{d}}$ Ethanol tolerance $(\% \mathrm{v} / \mathrm{v})$ was defined as the ethanol produced from a high sugar must. ${ }^{\mathrm{e}}$ The final optical density $\left(\mathrm{A}_{600}\right)$ of $\mathrm{A} 1$ was not available (n/a) due to complete light scattering due to flocculation. ${ }^{\mathrm{f}}$ Foam height and sulfur dioxide concentrations were assessed using additional fermentations. 
Although sulfur dioxide production is generally not considered a selection criterion for wine yeasts, over abundance could inhibit the growth or cause stuck malolactic fermentations. Yeast strains in this research produced $\mathrm{SO}_{2}$ concentrations in the range of $10-50 \mathrm{mg} \cdot \mathrm{L}^{-1}$ (Table 1). Although this was slightly higher than the usual $\left(10-30 \mathrm{mg} \cdot \mathrm{L}^{-1}\right)$, it was believed attributed to the need to use a nutrient-poor synthetic grape must. Interestingly, the individual Burgundian isolates produced more $\mathrm{SO}_{2}$ than $\mathrm{AMH}$, AWRI796, and BGY, but similar concentrations to Lalvin RA17 (RA17) and Lalvin Bourgorouge RC212 (RC212) (Table 1). The sulfur dioxide produced by the Burgundian isolates would not be expected to adversely impact malolactic fermentations, for most $O$. oeni strains can tolerate $15 \mathrm{mg} \cdot \mathrm{L}^{-1}$ free- and $60-100 \mathrm{mg} \cdot \mathrm{L}^{-1}$ total $\mathrm{SO}_{2}$, To verify this, assays were conducted to quantify malic acid consumption and lactic acid production for the Pinot noir fermentations (data not shown). Wines produced by the Burgundian strains completed malolactic fermentation as expected and had similar malic and lactic acid concentrations as the majority of the commercial strains. Therefore the Burgundian strains were considered enologically equivalent.

\subsection{Analysis of Volatile Compounds}

GC-MS of the headspace volatile compounds of Pinot noir wines revealed 25 quantifiable compounds. Analysis of variance (ANOVA) showed significant differences among the yeasts for nine higher alcohols (Table 2), seven ethyl esters (Table 3 ) and five acetate esters, two aldehydes, one acid and one acetal (Table 4) at $22{ }^{\circ} \mathrm{C}$ and $27{ }^{\circ} \mathrm{C}$, except for 1-hexanol at $27{ }^{\circ} \mathrm{C}$ (Table 3), phenylethanol at $27{ }^{\circ} \mathrm{C}$ (Table 2) and hexyl acetate at $22{ }^{\circ} \mathrm{C}$ (Table 4). While differences for a particular yeast were really apparent, differences among the classes of yeast (industrial, individual- and mixed-Burgundian) were not. As such, it was desirable to use a multivariate statistical tool, principal component analysis (PCA), in order to extract the pattern of volatiles among the yeasts and between the temperatures. PCA allowed all 25 volatiles (higher alcohols, ethyl esters, acetate esters, aldehydes, acid, acetal) to be considered together.

Principal components (PC) 1, 2 and 3 explained 28.4\%, 23.2\%, and $14.9 \%$ of the variation in the data set, respectively (Figure 3), with the vector loadings for the volatile compounds provided in Table 5. Volatile compounds with loadings greater than 1.2 were considered 'heavily loaded' and accounted for the majority of the variation among the yeasts.

Wines were clearly grouped according to their fermentation temperature $\left(22^{\circ} \mathrm{C}, 27^{\circ} \mathrm{C}\right)$ (Figure 3 ), but yeast groups were more difficult to discern in a three-dimensional plot. Therefore, two-dimensional plots (Figure 4a-c) were prepared showing PC 1 vs PC 2 (Figure 4a), PC 2 versus PC 3 (Figure 4b) and PC 1 versus PC 3 (Figure 4c).

In Figure 4a, PC 1 was most heavily loaded in the positive direction with five ethyl esters (ethyl octanoate, ethyl hexanoate, ethyl butanoate, ethyl laurate, ethyl decanoate) and three acetate esters (ethyl acetate, hexyl acetate, isobutyl acetate, isoamyl acetate), as denoted by the high positive PC 1 values (Table 5). PC 1 was most heavily loaded in the negative direction with three higher alcohols (2-methyl-1-butanol, phenylethanol, 1-hexanol), as denoted by the negative PC 2 values (Table 5). Wine located on the lower left hand side of the plot (Figure 4a), such as the industrial wines fermented at $27^{\circ} \mathrm{C}$, had higher concentrations of these higher alcohols, while the remaining wines located on the right hand side of the plot (Figure 4a), had higher concentrations of the aforementioned ethyl and acetate esters. 
Table 2. Higher alcohols $\left(\mathrm{mg} \cdot \mathrm{L}^{-1}\right)^{\mathrm{a}, \mathrm{b}}$ in Pinot noir fermented with industrial strains and individual- and mixed-Burgundian $S$. cerevisiae isolates at $22{ }^{\circ} \mathrm{C}$ and $27^{\circ} \mathrm{C}$. For each determination, strain and temperature effects are shown with subscripts and $p$ values, respectively.

\begin{tabular}{|c|c|c|c|c|c|c|c|c|c|c|}
\hline \multirow{2}{*}{\multicolumn{2}{|c|}{$\begin{array}{c}\text { Yeast } \\
\text { Strain or Isolate }\end{array}$}} & \multicolumn{2}{|c|}{ 1,3-butanediol } & \multirow{3}{*}{$\frac{p^{\mathrm{c}}}{*}$} & \multicolumn{2}{|c|}{ 2,3-butanediol } & \multirow{3}{*}{$\begin{array}{l}p \\
*\end{array}$} & \multicolumn{2}{|c|}{ 2-methyl-1-butanol } & \multirow{3}{*}{$\begin{array}{l}p \\
\mathrm{~ns}\end{array}$} \\
\hline & & \multirow{2}{*}{$\frac{22{ }^{\circ} \mathbf{C}}{3.150 \text { bcde }}$} & \multirow{2}{*}{$\begin{array}{c}\mathbf{2 7 ^ { \circ } \mathrm { C }} \\
7.216 \mathrm{e}\end{array}$} & & $22^{\circ} \mathrm{C}$ & $27^{\circ} \mathrm{C}$ & & $22{ }^{\circ} \mathrm{C}$ & $27^{\circ} \mathrm{C}$ & \\
\hline \multirow{5}{*}{ Industrial } & AMH & & & & 0.929 bcde & $2.001 \mathrm{e}$ & & $1.693 \mathrm{a}$ & $2.024 \mathrm{a}$ & \\
\hline & AWRI796 & 2.651 abcde & $5.585 \mathrm{~cd}$ & $* *$ & $0.854 \mathrm{abcd}$ & $1.497 \mathrm{~cd}$ & $*$ & $2.089 \mathrm{bcd}$ & $2.416 \mathrm{bcd}$ & $\mathrm{ns}$ \\
\hline & BGY & 2.773 abcde & $4.336 \mathrm{ab}$ & $* *$ & 0.913 bcde & $1.213 \mathrm{abc}$ & $* *$ & $2.433 \mathrm{ef}$ & $2.481 \mathrm{~cd}$ & $\mathrm{~ns}$ \\
\hline & RA17 & $3.359 \mathrm{de}$ & $5.219 \mathrm{bcd}$ & $*$ & $1.000 \mathrm{cde}$ & $1.405 \mathrm{bcd}$ & $*$ & $1.951 \mathrm{ab}$ & $2.392 \mathrm{bcd}$ & ns \\
\hline & RC212 & $2.392 \mathrm{abcd}$ & $3.886 \mathrm{a}$ & $* * *$ & $0.773 \mathrm{abc}$ & $1.050 \mathrm{a}$ & $* *$ & $2.053 \mathrm{bc}$ & $2.674 \mathrm{~d}$ & $* *$ \\
\hline \multirow{3}{*}{$\begin{array}{c}\text { Individual } \\
\text { Burgundian }\end{array}$} & A1 & $2.112 \mathrm{a}$ & $4.226 \mathrm{ab}$ & $* * *$ & $0.669 \mathrm{a}$ & $1.166 \mathrm{ab}$ & $* * *$ & $2.357 \mathrm{def}$ & $2.282 \mathrm{abc}$ & $\mathrm{ns}$ \\
\hline & A2 & $2.317 \mathrm{abc}$ & $4.663 \mathrm{abc}$ & $* *$ & $0.790 \mathrm{abc}$ & $1.322 \mathrm{abcd}$ & $* *$ & $2.315 \mathrm{cdef}$ & $2.140 \mathrm{ab}$ & ns \\
\hline & A3 & $2.239 \mathrm{ab}$ & $3.818 \mathrm{a}$ & $* * *$ & $0.748 \mathrm{ab}$ & $1.057 \mathrm{a}$ & $* * *$ & $2.090 \mathrm{bcd}$ & $2.074 \mathrm{a}$ & ns \\
\hline \multirow{5}{*}{$\begin{array}{c}\text { Mixed } \\
\text { Burgundian }\end{array}$} & M1 (1:1:1) & $3.610 \mathrm{e}$ & $5.893 \mathrm{~d}$ & $*$ & $1.110 \mathrm{e}$ & $1.524 \mathrm{~d}$ & ns & $2.306 \mathrm{cdef}$ & $2.309 \mathrm{abc}$ & $\mathrm{ns}$ \\
\hline & M2 $(1: 2: 3)$ & $3.554 \mathrm{e}$ & $5.801 \mathrm{~d}$ & $*$ & $1.087 \mathrm{de}$ & $1.549 \mathrm{~d}$ & $*$ & $2.265 \mathrm{cde}$ & $2.484 \mathrm{~cd}$ & $*$ \\
\hline & $\operatorname{M3}(3: 2: 1)$ & $3.234 \mathrm{cde}$ & $5.734 \mathrm{~cd}$ & $* *$ & 0.977 bcde & $1.510 \mathrm{~cd}$ & $* *$ & $2.330 \mathrm{cdef}$ & $2.278 \mathrm{abc}$ & ns \\
\hline & M4 (1:3:2) & $3.575 \mathrm{e}$ & $5.187 \mathrm{bcd}$ & $*$ & $1.075 \mathrm{de}$ & $1.343 \mathrm{abcd}$ & ns & $2.580 \mathrm{f}$ & $2.299 \mathrm{abc}$ & ns \\
\hline & Range & $2.112-3.651$ & $3.818-7.216$ & & $0.669-1.110$ & $\begin{array}{l}1.050- \\
2.001\end{array}$ & & $1.693-2.580$ & $2.024-2.674$ & \\
\hline \multirow{2}{*}{\multicolumn{2}{|c|}{$\begin{array}{c}\text { Yeast } \\
\text { Strain or Isolate }\end{array}$}} & \multicolumn{2}{|c|}{ 3-methyl-1-butanol } & \multirow[b]{2}{*}{$p$} & \multicolumn{2}{|c|}{ Butanol } & & \multicolumn{2}{|c|}{ 1-hexanol } & \\
\hline & & $22{ }^{\circ} \mathrm{C}$ & $27^{\circ} \mathrm{C}$ & & $22{ }^{\circ} \mathrm{C}$ & $27^{\circ} \mathrm{C}$ & $p$ & $22^{\circ} \mathrm{C}$ & $27^{\circ} \mathrm{C}$ & $p$ \\
\hline \multirow{5}{*}{ Industrial } & AMH & $8.229 \mathrm{a}$ & $9.309 \mathrm{a}$ & ns & $0.185 \mathrm{~cd}$ & $0.270 \mathrm{~cd}$ & $* * *$ & $2.206 \mathrm{ab}$ & 2.520 & $\mathrm{~ns}$ \\
\hline & AWRI796 & $9.840 \mathrm{bcd}$ & $10.815 \mathrm{bcd}$ & ns & $0.169 \mathrm{bc}$ & $0.317 \mathrm{e}$ & $* * *$ & $2.413 \mathrm{abc}$ & 2.354 & ns \\
\hline & BGY & $10.949 \mathrm{de}$ & $11.003 \mathrm{~cd}$ & ns & $0.169 \mathrm{bc}$ & $0.212 \mathrm{a}$ & $*$ & $2.649 \mathrm{~cd}$ & 2.448 & ns \\
\hline & RA17 & $9.486 \mathrm{~b}$ & $11.004 \mathrm{~cd}$ & ns & $0.157 \mathrm{ab}$ & $0.225 \mathrm{ab}$ & $* *$ & $2.164 \mathrm{a}$ & 2.275 & $\mathrm{~ns}$ \\
\hline & RC212 & $9.605 \mathrm{bc}$ & $11.843 \mathrm{~d}$ & $*$ & $0.263 \mathrm{f}$ & $0.517 \mathrm{f}$ & $* * *$ & $2.214 \mathrm{ab}$ & 2.600 & ns \\
\hline \multirow{3}{*}{$\begin{array}{l}\text { Individual } \\
\text { Burgundian }\end{array}$} & A1 & $11.518 \mathrm{e}$ & $10.888 \mathrm{bcd}$ & ns & $0.147 \mathrm{a}$ & $0.227 \mathrm{ab}$ & $* * *$ & $2.499 \mathrm{bc}$ & 2.096 & $*$ \\
\hline & $\mathbf{A 2}$ & $10.736 \mathrm{cde}$ & $9.745 \mathrm{ab}$ & $*$ & $0.208 \mathrm{e}$ & $0.280 \mathrm{~cd}$ & $*$ & $2.497 \mathrm{abc}$ & 2.110 & $*$ \\
\hline & A3 & $9.921 \mathrm{bcd}$ & $9.360 \mathrm{a}$ & ns & 0.189 cde & $0.290 \mathrm{de}$ & $* * *$ & $2.351 \mathrm{abc}$ & 2.005 & * \\
\hline
\end{tabular}


Table 2. Cont.

\begin{tabular}{|c|c|c|c|c|c|c|c|c|c|c|}
\hline \multirow{2}{*}{\multicolumn{2}{|c|}{$\begin{array}{c}\text { Yeast } \\
\text { Strain or Isolate } \\
\end{array}$}} & \multicolumn{2}{|c|}{ 3-methyl-1-butanol } & \multirow{3}{*}{$\begin{array}{l}\boldsymbol{p} \\
\mathrm{ns}\end{array}$} & \multicolumn{2}{|c|}{ Butanol } & \multirow{3}{*}{$\begin{array}{c}\boldsymbol{p} \\
* * *\end{array}$} & \multicolumn{2}{|c|}{ 1-hexanol } & \multirow{3}{*}{$\begin{array}{l}p \\
\mathrm{~ns}\end{array}$} \\
\hline & & \multirow{2}{*}{$\begin{array}{c}\mathbf{2 2}^{\circ} \mathbf{C} \\
10.693 \text { bcde }\end{array}$} & \multirow{2}{*}{$\frac{\mathbf{2 7}{ }^{\circ} \mathbf{C}}{10.648 \mathrm{bcd}}$} & & \multirow{2}{*}{$\frac{22^{\circ} \mathbf{C}}{0.184 \mathrm{~cd}}$} & \multirow{2}{*}{$\begin{array}{c}\mathbf{2 7 ^ { \circ } \mathbf { C }} \\
0.271 \mathrm{~cd}\end{array}$} & & \multirow{2}{*}{$\frac{22{ }^{\circ} \mathbf{C}}{2.54 \mathrm{bcd}}$} & \multirow{2}{*}{$\begin{array}{l}27^{\circ} \mathbf{C} \\
2.171\end{array}$} & \\
\hline & M1 (1:1:1) & & & & & & & & & \\
\hline Mixed & M2 (1:2:3) & 10.492 bcde & $11.197 \mathrm{~cd}$ & $*$ & $0.194 \mathrm{de}$ & $0.254 \mathrm{bc}$ & $*$ & $2.487 \mathrm{abc}$ & 2.393 & $\mathrm{~ns}$ \\
\hline \multirow[t]{3}{*}{ Burgundian } & M3 (3:2:1) & $10.828 \mathrm{cde}$ & $10.541 \mathrm{abc}$ & $\mathrm{ns}$ & $0.171 \mathrm{bc}$ & $0.272 \mathrm{~cd}$ & $* * *$ & $2.533 \mathrm{bcd}$ & 2.151 & $\mathrm{~ns}$ \\
\hline & M4 (1:3:2) & $11.712 \mathrm{e}$ & $10.209 \mathrm{abc}$ & ns & $0.203 \mathrm{de}$ & $0.261 \mathrm{~cd}$ & $*$ & $2.841 \mathrm{~d}$ & 2.187 & * \\
\hline & Range & $8.229-11.712$ & $9.309-11.843$ & & $0.169-0.263$ & $0.227-0.317$ & & $2.164-2.841$ & $2.005-2.600$ & \\
\hline \multicolumn{2}{|c|}{ Yeast } & \multicolumn{2}{|c|}{ Isobutanol } & \multirow[b]{2}{*}{$p$} & \multicolumn{2}{|c|}{ Phenylethanol } & \multirow[b]{2}{*}{$p$} & \multicolumn{2}{|c|}{ Propanol } & \\
\hline Strain c & solate & $22^{\circ} \mathrm{C}$ & $27^{\circ} \mathrm{C}$ & & $22{ }^{\circ} \mathrm{C}$ & $27^{\circ} \mathrm{C}$ & & $22{ }^{\circ} \mathrm{C}$ & $27^{\circ} \mathrm{C}$ & $p$ \\
\hline \multirow{5}{*}{ Industrial } & AMH & $31.380 \mathrm{a}$ & $28.825 \mathrm{a}$ & $\mathrm{ns}$ & $0.472 \mathrm{a}$ & 0.827 & $* *$ & $12.845 \mathrm{f}$ & $11.804 \mathrm{e}$ & ns \\
\hline & AWRI796 & $50.592 \mathrm{bc}$ & $53.129 \mathrm{~b}$ & ns & $0.709 \mathrm{~cd}$ & 0.783 & $\mathrm{~ns}$ & $11.198 \mathrm{de}$ & $12.111 \mathrm{e}$ & ns \\
\hline & BGY & $71.731 \mathrm{~d}$ & $72.157 \mathrm{~d}$ & $\mathrm{~ns}$ & $0.680 \mathrm{bcd}$ & 0.829 & $\mathrm{~ns}$ & $8.654 \mathrm{ab}$ & $7.456 \mathrm{a}$ & $\mathrm{ns}$ \\
\hline & RA17 & $53.548 \mathrm{bc}$ & $66.743 \mathrm{~cd}$ & $\mathrm{~ns}$ & $0.565 \mathrm{ab}$ & 0.745 & $\mathrm{~ns}$ & $8.179 \mathrm{a}$ & $7.837 \mathrm{ab}$ & $\mathrm{ns}$ \\
\hline & $\mathrm{RC212}$ & $72.158 \mathrm{~d}$ & $110.846 \mathrm{f}$ & $* *$ & $0.570 \mathrm{ab}$ & 0.732 & $*$ & $8.221 \mathrm{a}$ & $9.086 \mathrm{~cd}$ & ns \\
\hline \multirow{3}{*}{$\begin{array}{l}\text { Individual } \\
\text { Burgundian }\end{array}$} & A1 & $62.119 \mathrm{~cd}$ & $87.520 \mathrm{e}$ & $* *$ & $0.652 \mathrm{bc}$ & 0.672 & $\mathrm{~ns}$ & $13.487 \mathrm{f}$ & $14.164 \mathrm{f}$ & $\mathrm{ns}$ \\
\hline & A2 & $44.142 \mathrm{~b}$ & $55.413 \mathrm{~b}$ & $\mathrm{~ns}$ & $0.623 \mathrm{bc}$ & 0.618 & $\mathrm{~ns}$ & $9.555 \mathrm{bc}$ & $9.217 \mathrm{~cd}$ & $\mathrm{~ns}$ \\
\hline & $\mathbf{A 3}$ & $43.416 \mathrm{ab}$ & $51.732 \mathrm{~b}$ & $*$ & $0.632 \mathrm{bc}$ & 0.641 & $\mathrm{~ns}$ & $8.815 \mathrm{ab}$ & $7.767 \mathrm{ab}$ & * \\
\hline \multirow{5}{*}{$\begin{array}{c}\text { Mixed } \\
\text { Burgundian }\end{array}$} & M1 (1:1:1) & $58.954 \mathrm{c}$ & $56.836 \mathrm{bc}$ & $\mathrm{ns}$ & $0.645 \mathrm{bc}$ & 0.682 & $\mathrm{~ns}$ & $10.984 \mathrm{de}$ & $9.908 \mathrm{~d}$ & $\mathrm{~ns}$ \\
\hline & M2 (1:2:3) & $56.976 \mathrm{c}$ & $56.554 \mathrm{bc}$ & $\mathrm{ns}$ & $0.636 \mathrm{bc}$ & 0.746 & $\mathrm{~ns}$ & $9.989 \mathrm{c}$ & $8.589 \mathrm{bc}$ & $\mathrm{ns}$ \\
\hline & M3 (3:2:1) & $60.020 \mathrm{~cd}$ & $58.112 \mathrm{bc}$ & $\mathrm{ns}$ & $0.713 \mathrm{~cd}$ & 0.661 & $\mathrm{~ns}$ & $11.775 \mathrm{e}$ & $11.122 \mathrm{e}$ & $\mathrm{ns}$ \\
\hline & M4 (1:3:2) & $53.698 \mathrm{bc}$ & $51.769 \mathrm{~b}$ & $\mathrm{~ns}$ & $0.804 \mathrm{~d}$ & 0.673 & $\mathrm{~ns}$ & $10.258 \mathrm{~cd}$ & $8.380 \mathrm{abc}$ & ** \\
\hline & Range & $31.380-72.158$ & $28.825-87.520$ & & $0.472-0.804$ & $0.661-0.829$ & & $8.179-12.845$ & $7.456-14.164$ & \\
\hline
\end{tabular}

${ }^{a}$ the mean values of the biological replicates of each yeast strain were shown $(n=3) .{ }^{\mathrm{b}}$ yeast strain means not sharing the same subscript are significantly $(p \leq 0.05)$ different at each temperature. ${ }^{\mathrm{c}} \mathrm{ns},{ }^{*}, * *, * * *$ indicates non-significant and significant at $p \leq 0.05,0.01$ and 0.001 , respectively, for temperature effects. 
Table 3. Ethyl esters $\left(\mathrm{mg} \cdot \mathrm{L}^{-1}\right)$ a,b in Pinot noir fermented with industrial strains and individual- and mixed-Burgundian $S$. cerevisiae isolates, at $22{ }^{\circ} \mathrm{C}$ and $27^{\circ} \mathrm{C}$. For each determination, strain and temperature effects are shown with subscripts and $p$ values, respectively.

\begin{tabular}{|c|c|c|c|c|c|c|c|c|c|c|}
\hline \multirow{2}{*}{\multicolumn{2}{|c|}{$\begin{array}{c}\text { Yeast } \\
\text { Strain or Isolate }\end{array}$}} & \multicolumn{2}{|c|}{ Ethyl butanoate } & \multirow{2}{*}{$p^{\mathrm{c}}$} & \multicolumn{2}{|c|}{ Ethyl decanoate } & \multirow{2}{*}{$p$} & \multicolumn{2}{|c|}{ Ethyl hexanoate } & \multirow{2}{*}{$\boldsymbol{p}$} \\
\hline & & $22{ }^{\circ} \mathrm{C}$ & $27^{\circ} \mathrm{C}$ & & $22{ }^{\circ} \mathrm{C}$ & $27^{\circ} \mathrm{C}$ & & $22{ }^{\circ} \mathrm{C}$ & $27^{\circ} \mathrm{C}$ & \\
\hline \multirow{5}{*}{ Industrial } & АМH & $2.689 \mathrm{ab}$ & $1.707 \mathrm{a}$ & $* * *$ & $0.031 \mathrm{~d}$ & $0.020 \mathrm{ab}$ & $* *$ & $0.060 \mathrm{~d}$ & $0.040 \mathrm{ab}$ & $* * *$ \\
\hline & AWRI796 & $3.232 \mathrm{cde}$ & $2.327 \mathrm{bc}$ & ns & $0.025 \mathrm{~cd}$ & $0.024 \mathrm{abc}$ & ns & $0.059 \mathrm{~cd}$ & $0.043 \mathrm{bcd}$ & $*$ \\
\hline & BGY & $2.368 \mathrm{a}$ & $2.193 \mathrm{abc}$ & ns & $0.021 \mathrm{bc}$ & $0.017 \mathrm{a}$ & $\mathrm{ns}$ & $0.046 \mathrm{ab}$ & $0.036 \mathrm{a}$ & $*$ \\
\hline & RA17 & $2.862 \mathrm{bcd}$ & $2.180 \mathrm{abc}$ & $* * *$ & $0.022 \mathrm{bc}$ & $0.024 \mathrm{abc}$ & $\mathrm{ns}$ & $0.051 \mathrm{abc}$ & $0.041 \mathrm{abc}$ & $* *$ \\
\hline & $\mathrm{RC212}$ & $3.181 \mathrm{cde}$ & $2.116^{\mathrm{a} b c}$ & $*$ & $0.024 \mathrm{c}$ & $0.023 \mathrm{abc}$ & ns & $0.052 \mathrm{abc}$ & $0.040 \mathrm{abc}$ & ns \\
\hline \multirow{3}{*}{ Individual Burgundian } & A1 & $3.262 \mathrm{de}$ & $3.131 \mathrm{e}$ & $\mathrm{ns}$ & $0.025 \mathrm{~cd}$ & $0.034 \mathrm{e}$ & $*$ & $0.054 \mathrm{~cd}$ & $0.050 \mathrm{~d}$ & $\mathrm{~ns}$ \\
\hline & A2 & $2.286 \mathrm{a}$ & $2.107 \mathrm{ab}$ & ns & $0.015 \mathrm{ab}$ & $0.031 \mathrm{cde}$ & $* * *$ & $0.046 \mathrm{ab}$ & $0.046 \mathrm{~cd}$ & ns \\
\hline & $\mathbf{A 3}$ & $3.387 \mathrm{e}$ & $2.893 \mathrm{de}$ & $*$ & $0.023 \mathrm{c}$ & 0.026 bcde & $\mathrm{ns}$ & $0.053 \mathrm{bcd}$ & $0.041 \mathrm{abc}$ & $* *$ \\
\hline \multirow{4}{*}{ Mixed Burgundian } & M1 (1:1:1) & $3.275 \mathrm{de}$ & $3.080 \mathrm{e}$ & $\mathrm{ns}$ & $0.024 \mathrm{c}$ & 0.030 cde & $\mathrm{ns}$ & $0.054 \mathrm{~cd}$ & $0.048 \mathrm{~d}$ & $\mathrm{~ns}$ \\
\hline & M2 (1:2:3) & $3.316 \mathrm{e}$ & 2.626 cde & ns & $0.024 \mathrm{c}$ & $0.024 \mathrm{abc}$ & $\mathrm{ns}$ & $0.053 \mathrm{bcd}$ & $0.042 \mathrm{abc}$ & ns \\
\hline & M3 (3:2:1) & $3.252 \mathrm{de}$ & $3.117 \mathrm{e}$ & $\mathrm{ns}$ & $0.025 \mathrm{~cd}$ & $0.033 \mathrm{de}$ & $\mathrm{ns}$ & $0.054 \mathrm{~cd}$ & $0.050 \mathrm{~d}$ & $\mathrm{~ns}$ \\
\hline & M4 (1:3:2) & $2.826 \mathrm{bc}$ & $2.494 \mathrm{bcd}$ & ns & $0.013 \mathrm{a}$ & $0.025 \mathrm{bcd}$ & ns & $0.045 \mathrm{a}$ & $0.041 \mathrm{abc}$ & ns \\
\hline & Range & $2.368-3.316$ & $1.707-3.131$ & & $0.013-0.031$ & $0.017-0.034$ & & $0.045-0.060$ & $0.036-0.050$ & \\
\hline \multirow{2}{*}{\multicolumn{2}{|c|}{$\begin{array}{c}\text { Yeast } \\
\text { Strain or Isolate }\end{array}$}} & \multicolumn{2}{|c|}{ Ethyl lactate } & & \multicolumn{2}{|c|}{ Ethyl laurate } & \multicolumn{3}{|c|}{ Ethyl octanoate } & \\
\hline & & $22{ }^{\circ} \mathrm{C}$ & $27^{\circ} \mathrm{C}$ & $p$ & $22{ }^{\circ} \mathrm{C}$ & $27^{\circ} \mathrm{C}$ & $p$ & $22{ }^{\circ} \mathrm{C}$ & $27^{\circ} \mathrm{C}$ & $p$ \\
\hline \multirow{5}{*}{ Industrial } & AMH & $0.548 \mathrm{a}$ & $0.682 \mathrm{~b}$ & $*$ & $0.006 \mathrm{def}$ & $0.004 \mathrm{a}$ & $* *$ & $0.068 \mathrm{~d}$ & $0.035 \mathrm{a}$ & $* * *$ \\
\hline & AWRI796 & $0.847 \mathrm{ab}$ & $0.882 \mathrm{~cd}$ & ns & $0.007 \mathrm{ef}$ & $0.008 \mathrm{~b} \mathrm{~cd}$ & $\mathrm{~ns}$ & $0.053 \mathrm{bc}$ & $0.040 \mathrm{ab}$ & $\mathrm{ns}$ \\
\hline & BGY & $1.773 \mathrm{c}$ & $0.671 \mathrm{~b}$ & ns & $0.004 \mathrm{bcd}$ & $0.004 \mathrm{a}$ & ns & $0.046 \mathrm{abc}$ & $0.033 \mathrm{a}$ & ns \\
\hline & RA17 & $0.631 \mathrm{ab}$ & $0.726 \mathrm{~b}$ & ns & $0.004 \mathrm{abc}$ & $0.005 \mathrm{ab}$ & ns & $0.047 \mathrm{abc}$ & $0.040 \mathrm{ab}$ & ns \\
\hline & $\mathrm{RC212}$ & $0.753 \mathrm{ab}$ & $0.939 \mathrm{~d}$ & $* *$ & $0.005 \mathrm{~cd}$ & $0.006 \mathrm{ab}$ & ns & $0.046 \mathrm{abc}$ & $0.035 \mathrm{a}$ & ns \\
\hline \multirow{3}{*}{ Individual Burgundian } & A1 & $0.973 \mathrm{~b}$ & $0.936 \mathrm{~d}$ & $\mathrm{~ns}$ & $0.007 \mathrm{f}$ & $0.009 \mathrm{~cd}$ & $* *$ & $0.057 \mathrm{~cd}$ & $0.052 \mathrm{~cd}$ & $\mathrm{~ns}$ \\
\hline & A2 & $0.749 \mathrm{ab}$ & $0.671 \mathrm{~b}$ & ns & $0.002 \mathrm{ab}$ & $0.007 \mathrm{bc}$ & $* *$ & $0.043 \mathrm{ab}$ & $0.052 \mathrm{~cd}$ & $* * *$ \\
\hline & A3 & $0.724 \mathrm{ab}$ & $0.719 \mathrm{~b}$ & ns & $0.004 \mathrm{abc}$ & $0.006 \mathrm{ab}$ & $*$ & $0.055 \mathrm{bc}$ & $0.040 \mathrm{ab}$ & $*$ \\
\hline
\end{tabular}


Table 3. Cont

\begin{tabular}{|c|c|c|c|c|c|c|c|c|c|c|}
\hline \multirow{2}{*}{\multicolumn{2}{|c|}{$\begin{array}{c}\text { Yeast } \\
\text { Strain or Isolate }\end{array}$}} & \multicolumn{2}{|c|}{ Ethyl lactate } & \multirow{2}{*}{$p$} & \multicolumn{2}{|c|}{ Ethyl laurate } & \multirow{2}{*}{$p$} & \multicolumn{2}{|c|}{ Ethyl laurate } & \multirow{2}{*}{$p$} \\
\hline & & $22^{\circ} \mathrm{C}$ & $27^{\circ} \mathrm{C}$ & & $22^{\circ} \mathrm{C}$ & $27^{\circ} \mathrm{C}$ & & $22^{\circ} \mathrm{C}$ & $27^{\circ} \mathrm{C}$ & \\
\hline \multirow{5}{*}{ Mixed Burgundian } & M1 (1:1:1) & $0.817 \mathrm{ab}$ & not quantifiable & $* * *$ & $0.005 \mathrm{~cd}$ & $0.009 \mathrm{~d}$ & $*$ & $0.057 \mathrm{~cd}$ & $0.048 \mathrm{bcd}$ & $\mathrm{ns}$ \\
\hline & M2 (1:2:3) & $0.780 \mathrm{ab}$ & $0.799 \mathrm{bc}$ & $\mathrm{ns}$ & $0.004 \mathrm{~cd}$ & $0.007 \mathrm{bcd}$ & ns & $0.056 \mathrm{~cd}$ & $0.040 \mathrm{ab}$ & ns \\
\hline & M3 (3:2:1) & $0.857 \mathrm{ab}$ & $0.766 \mathrm{bc}$ & $\mathrm{ns}$ & 0.005 cde & $0.009 \mathrm{~d}$ & $*$ & $0.057 \mathrm{~cd}$ & $0.055 \mathrm{~d}$ & $\mathrm{~ns}$ \\
\hline & M4 (1:3:2) & $0.902 \mathrm{ab}$ & $0.698 \mathrm{~b}$ & $\mathrm{~ns}$ & $0.002 \mathrm{a}$ & $0.006 \mathrm{~b}$ & $*$ & $0.036 \mathrm{a}$ & $0.042 \mathrm{abc}$ & $\mathrm{ns}$ \\
\hline & Range & $0.548-1.773$ & $0.671-0.939$ & & $0.002-0.007$ & $0.004-0.009$ & & $0.036-0.068$ & $0.035-0.055$ & \\
\hline
\end{tabular}

\begin{tabular}{ccccc}
\hline \multirow{2}{*}{ Yeast } & & \multicolumn{2}{c}{ Ethyl palmitate } & \\
\cline { 3 - 4 } Strain or Isolate & & $\mathbf{2 2}{ }^{\circ} \mathbf{C}$ & $\mathbf{2 7}{ }^{\circ} \mathbf{C}$ & \\
\hline & AMH & $0.045 \mathrm{a}$ & $0.054 \mathrm{a}$ & $\mathrm{ns}$ \\
AWRI796 & $0.118 \mathrm{ef}$ & $0.133 \mathrm{~d}$ & $\mathrm{~ns}$ \\
Industrial & $\mathbf{B G Y}$ & $0.072 \mathrm{abc}$ & $0.083 \mathrm{~b}$ & $\mathrm{~ns}$ \\
& $\mathbf{R A 1 7}$ & $0.068 \mathrm{abc}$ & $0.101 \mathrm{bc}$ & $*$ \\
& $\mathbf{R C 2 1 2}$ & $0.103 \mathrm{def}$ & $0.143 \mathrm{~d}$ & $\mathrm{~ns}$ \\
\hline \multirow{5}{*}{ Individual Burgundian } & $\mathbf{A 1}$ & $0.123 \mathrm{f}$ & $0.145 \mathrm{~d}$ & $\mathrm{~ns}$ \\
& $\mathbf{A 2}$ & $0.056 \mathrm{ab}$ & $0.101 \mathrm{bc}$ & $*$ \\
& $\mathbf{A 3}$ & $0.090 \mathrm{cde}$ & $0.101 \mathrm{bc}$ & $\mathrm{ns}$ \\
\hline \multirow{5}{*}{ Mixed Burgundian } & M1 (1:1:1) & $0.105 \mathrm{ef}$ & $0.139 \mathrm{~d}$ & $\mathrm{~ns}$ \\
& M2 (1:2:3) & $0.108 \mathrm{ef}$ & $0.120 \mathrm{~cd}$ & $\mathrm{~ns}$ \\
& M3 (3:2:1) & $0.114 \mathrm{ef}$ & $0.127 \mathrm{~cd}$ & $\mathrm{~ns}$ \\
& M4 (1:3:2) & $0.077 \mathrm{bcd}$ & $0.090 \mathrm{~b}$ & $\mathrm{~ns}$ \\
\hline & Range & $0.045-0.123$ & $0.054-0.133$ & \\
\hline
\end{tabular}

${ }^{a}$ the mean values of the biological replicates of each yeast strain were shown $(n=3){ }^{\mathrm{b}}$ yeast strain means not sharing the same subscript are significantly $(p \leq 0.05)$ different at each temperature. ${ }^{\mathrm{c}} \mathrm{ns}, *, * * * * *$ indicates non-significant and significant at $p \leq 0.05,0.01$ and 0.001 , respectively, for the temperature effects. 
Table 4. Acetate esters, aldehydes, acid and acetal $\left(\mathrm{mg} \cdot \mathrm{L}^{-1}\right){ }^{\mathrm{a}, \mathrm{b}}$ in Pinot noir fermented by industrial strains and individual- and mixed-Burgundian S. cerevisiae isolates, at $22^{\circ} \mathrm{C}$ and $27^{\circ} \mathrm{C}$. For each determination, strain and temperature effects are shown with subscripts and $p$ values, respectively. For each determination, strain and temperature effects are shown with subscripts and $p$ values, respectively.

\begin{tabular}{|c|c|c|c|c|c|c|c|c|c|c|}
\hline \multirow{2}{*}{\multicolumn{2}{|c|}{$\begin{array}{c}\text { Yeast } \\
\text { Strain or Isolate }\end{array}$}} & \multicolumn{2}{|c|}{ Ethyl acetate } & \multirow{2}{*}{$p^{\mathrm{c}}$} & \multicolumn{2}{|c|}{ Hexyl acetate } & \multirow{2}{*}{$p$} & \multicolumn{2}{|c|}{ Isoamyl acetate } & \multirow{2}{*}{$p$} \\
\hline & & $22{ }^{\circ} \mathrm{C}$ & $27^{\circ} \mathrm{C}$ & & $22{ }^{\circ} \mathrm{C}$ & $27^{\circ} \mathrm{C}$ & & $22{ }^{\circ} \mathrm{C}$ & $27^{\circ} \mathrm{C}$ & \\
\hline \multirow{5}{*}{ Industrial } & AMH & $10.039 \mathrm{bc}$ & $8.968 \mathrm{ab}$ & ns & 0.029 & $0.017 \mathrm{a}$ & ns & $0.203 \mathrm{abcd}$ & $0.148 \mathrm{a}$ & ns \\
\hline & AWRI796 & 9.889 bc & $10.191 \mathrm{bcd}$ & $* *$ & 0.022 & $0.020 \mathrm{ab}$ & ns & $0.188 \mathrm{abc}$ & $0.213 \mathrm{bcd}$ & ns \\
\hline & BGY & $10.083 \mathrm{bc}$ & $9.636 \mathrm{abc}$ & $\mathrm{ns}$ & 0.016 & $0.018 \mathrm{a}$ & $\mathrm{ns}$ & $0.171 \mathrm{a}$ & $0.184 \mathrm{abc}$ & ns \\
\hline & RA17 & $9.944 \mathrm{bc}$ & $10.111 \mathrm{bcd}$ & $*$ & 0.027 & $0.027 \mathrm{abcd}$ & $\mathrm{ns}$ & $0.228 \mathrm{bcd}$ & $0.255 \mathrm{def}$ & ns \\
\hline & RC212 & $8.824 \mathrm{a}$ & $8.615 \mathrm{a}$ & ns & 0.022 & $0.016 \mathrm{a}$ & ns & $0.190 \mathrm{abc}$ & $0.178 \mathrm{ab}$ & ns \\
\hline \multirow{3}{*}{$\begin{array}{l}\text { Individual } \\
\text { Burgundian }\end{array}$} & A1 & $10.467 \mathrm{c}$ & $11.271 \mathrm{de}$ & ns & 0.024 & $0.036 \mathrm{~d}$ & ns & $0.235 \mathrm{~cd}$ & $0.320 \mathrm{~g}$ & $*$ \\
\hline & $\mathbf{A 2}$ & $9.335 \mathrm{ab}$ & $10.342 \mathrm{bcd}$ & $*$ & 0.015 & $0.033 \mathrm{~cd}$ & $* * *$ & $0.167 \mathrm{a}$ & $0.267 \mathrm{defg}$ & $* * *$ \\
\hline & A3 & $10.077 \mathrm{bc}$ & $9.342 \mathrm{ab}$ & ns & 0.025 & $0.025 \mathrm{abcd}$ & ns & $0.211 \mathrm{abcd}$ & $0.222 \mathrm{bcd}$ & $\mathrm{ns}$ \\
\hline \multirow{5}{*}{$\begin{array}{c}\text { Mixed } \\
\text { Burgundian }\end{array}$} & M1 (1:1:1) & $10.613 \mathrm{c}$ & $11.471 \mathrm{de}$ & $\mathrm{ns}$ & 0.027 & $0.030 \mathrm{bcd}$ & $\mathrm{ns}$ & $0.234 \mathrm{~cd}$ & $0.291 \mathrm{efg}$ & $\mathrm{ns}$ \\
\hline & M2 (1:2:3) & $10.850 \mathrm{c}$ & $10.994 \mathrm{cde}$ & $*$ & 0.027 & $0.020 \mathrm{ab}$ & ns & $0.237 \mathrm{~d}$ & $0.225 \mathrm{bcd}$ & ns \\
\hline & M3 (3:2:1) & $10.599 \mathrm{c}$ & $11.807 \mathrm{e}$ & ns & 0.027 & $0.032 \mathrm{~cd}$ & ns & $0.241 \mathrm{~d}$ & $0.305 \mathrm{fg}$ & ns \\
\hline & M4 (1:3:2) & $10.360 \mathrm{c}$ & $9.751 \mathrm{abc}$ & ns & 0.016 & $0.024 \mathrm{abc}$ & ns & $0.182 \mathrm{ab}$ & $0.241 \mathrm{cde}$ & ns \\
\hline & Range & $8.824-10.850$ & $8.615-11.807$ & & $0.016-0.029$ & $0.016-0.033$ & & $0.167-0.241$ & $0.148-0.320$ & \\
\hline \multirow{2}{*}{\multicolumn{2}{|c|}{$\begin{array}{c}\text { Yeast } \\
\text { Strain or Isolate }\end{array}$}} & \multicolumn{2}{|c|}{ Isobutyl acetate } & & \multicolumn{2}{|c|}{ Methyl acetate } & & \multicolumn{2}{|c|}{ Acetaldehyde } & \\
\hline & & $22{ }^{\circ} \mathrm{C}$ & $27^{\circ} \mathrm{C}$ & $p$ & $22{ }^{\circ} \mathrm{C}$ & $27^{\circ} \mathrm{C}$ & $p$ & $22{ }^{\circ} \mathrm{C}$ & $27^{\circ} \mathrm{C}$ & $p$ \\
\hline \multirow{5}{*}{ Industrial } & AMH & $0.00091 \mathrm{a}$ & $0.00071 \mathrm{a}$ & $* *$ & $0.889 \mathrm{a}$ & $0.784 \mathrm{a}$ & ns & $1.026 \mathrm{~cd}$ & $0.967 \mathrm{bcd}$ & ns \\
\hline & AWRI796 & $0.00105 \mathrm{ab}$ & $0.00137 \mathrm{~b}$ & ns & $1.245 \mathrm{~cd}$ & $1.041 \mathrm{bc}$ & ns & $0.504 \mathrm{a}$ & $0.614 \mathrm{a}$ & $*$ \\
\hline & BGY & $0.00148 \mathrm{de}$ & $0.00187 \mathrm{~cd}$ & ns & $1.105 \mathrm{bc}$ & $1.077 \mathrm{bc}$ & ns & $0.670 \mathrm{a}$ & $0.690 \mathrm{ab}$ & ns \\
\hline & RA17 & $0.00125 \mathrm{bcd}$ & $0.00194 \mathrm{cde}$ & ns & $0.996 \mathrm{ab}$ & $0.932 \mathrm{ab}$ & ns & $1.339 \mathrm{e}$ & $1.357 \mathrm{ef}$ & ns \\
\hline & RC212 & $0.00158 \mathrm{e}$ & 0.00202 cde & $* *$ & $1.304 \mathrm{~d}$ & $1.126 \mathrm{~cd}$ & ns & $0.871 \mathrm{bc}$ & $0.803 \mathrm{ab}$ & ns \\
\hline \multirow{3}{*}{$\begin{array}{l}\text { Individual } \\
\text { Burgundian }\end{array}$} & A1 & $0.00155 \mathrm{e}$ & $0.00286 \mathrm{f}$ & ns & $1.311 \mathrm{~d}$ & $1.175 \mathrm{cde}$ & ns & $0.839 \mathrm{~b}$ & $0.947 \mathrm{bcd}$ & $\mathrm{ns}$ \\
\hline & A2 & $0.00096 \mathrm{a}$ & $0.00165 \mathrm{bc}$ & $* *$ & $0.946 \mathrm{a}$ & $1.017 \mathrm{bc}$ & ns & $0.979 \mathrm{bcd}$ & $1.156 \mathrm{cde}$ & ns \\
\hline & $\mathbf{A 3}$ & $0.00111 \mathrm{abc}$ & $0.00159 \mathrm{bc}$ & ns & $1.196 \mathrm{~cd}$ & $1.006 \mathrm{bc}$ & $*$ & $0.901 \mathrm{bcd}$ & $0.737 \mathrm{ab}$ & ns \\
\hline
\end{tabular}


Table 4. Cont.

\begin{tabular}{|c|c|c|c|c|c|c|c|c|c|c|}
\hline \multirow{2}{*}{\multicolumn{2}{|c|}{$\begin{array}{c}\text { Yeast } \\
\text { Strain or Isolate }\end{array}$}} & \multicolumn{2}{|c|}{ Isobutyl acetate } & \multirow{3}{*}{$\begin{array}{c}\boldsymbol{p} \\
* *\end{array}$} & \multicolumn{2}{|c|}{ Methyl acetate } & \multirow{3}{*}{$\begin{array}{c}\boldsymbol{p} \\
\mathrm{ns}\end{array}$} & \multicolumn{2}{|c|}{ Acetaldehyde } & \multirow{3}{*}{$\begin{array}{c}\boldsymbol{p} \\
* * *\end{array}$} \\
\hline & & \multirow{2}{*}{$\begin{array}{c}22^{\circ} \mathrm{C} \\
0.00133 \mathrm{cde}\end{array}$} & \multirow{2}{*}{$\begin{array}{c}\mathbf{2 7 ^ { \circ }}{ }^{\circ} \mathbf{C} \\
0.00215 \mathrm{de}\end{array}$} & & \multirow{2}{*}{$\frac{22^{\circ} \mathrm{C}}{1.183 \mathrm{~cd}}$} & \multirow{2}{*}{$\begin{array}{c}27^{\circ} \mathbf{C} \\
1.252 \mathrm{de}\end{array}$} & & $22^{\circ} \mathrm{C}$ & \multirow{2}{*}{$\begin{array}{c}\mathbf{2 7 ^ { \circ }} \mathbf{C} \\
1.377 \mathrm{ef}\end{array}$} & \\
\hline & M1 (1:1:1) & & & & & & & $0.923 \mathrm{bcd}$ & & \\
\hline Mixed & M2 (1:2:3) & $0.00133 \mathrm{cde}$ & $0.00176 \mathrm{bcd}$ & $*$ & $1.198 \mathrm{~cd}$ & $1.335 \mathrm{e}$ & ns & $1.009 \mathrm{~cd}$ & $1.538 \mathrm{f}$ & $\mathrm{ns}$ \\
\hline \multirow[t]{3}{*}{ Burgundian } & M3 (3:2:1) & $0.00140 \mathrm{de}$ & $0.00235 \mathrm{e}$ & $* *$ & $1.192 \mathrm{~cd}$ & $1.333 \mathrm{e}$ & ns & $1.049 \mathrm{~d}$ & $1.245 \mathrm{def}$ & ns \\
\hline & M4 (1:3:2) & $0.00104 \mathrm{ab}$ & $0.00166 \mathrm{bc}$ & ns & $1.172 \mathrm{~cd}$ & $1.065 \mathrm{bc}$ & ns & $0.937 \mathrm{bcd}$ & $0.939 \mathrm{bc}$ & $\mathrm{ns}$ \\
\hline & Range & $0.0009-0.00155$ & $0.00071-0.00235$ & & $0.889-1.311$ & $0.784-1.335$ & & $0.504-1.339$ & $0.737-1.538$ & \\
\hline \multicolumn{2}{|c|}{ Yeast } & \multicolumn{2}{|c|}{ Benzaldehyde } & & \multicolumn{2}{|c|}{ Acetic acid } & & \multicolumn{2}{|c|}{ 1,1-diethoxyacetal } & \\
\hline Strain & olate & $22^{\circ} \mathrm{C}$ & $27^{\circ} \mathrm{C}$ & $p$ & $22^{\circ} \mathrm{C}$ & $27^{\circ} \mathrm{C}$ & $p$ & $22^{\circ} \mathrm{C}$ & $27^{\circ} \mathrm{C}$ & $\boldsymbol{p}$ \\
\hline \multirow{5}{*}{ Industrial } & АМН & $0.029 \mathrm{ab}$ & $0.056 \mathrm{abcd}$ & $*$ & $0.387 \mathrm{a}$ & $0.427 \mathrm{ab}$ & $\mathrm{ns}$ & $2.833 \mathrm{~b}$ & $3.357 \mathrm{~d}$ & ns \\
\hline & AWRI796 & $0.056 \mathrm{fg}$ & 0.061 bcdef & ns & $0.394 \mathrm{a}$ & $0.375 \mathrm{a}$ & $* *$ & $2.049 \mathrm{a}$ & $2.364 \mathrm{~b}$ & ns \\
\hline & BGY & $0.045 \mathrm{de}$ & $0.056 \mathrm{abcd}$ & $*$ & $0.662 \mathrm{~b}$ & $0.658 \mathrm{~cd}$ & ns & $1.885 \mathrm{a}$ & $2.808 \mathrm{c}$ & ns \\
\hline & RA17 & $0.063 \mathrm{~g}$ & $0.068 \mathrm{f}$ & $\mathrm{ns}$ & $0.450 \mathrm{a}$ & $0.864 \mathrm{~d}$ & ns & $4.677 \mathrm{e}$ & $4.827 \mathrm{f}$ & $\mathrm{ns}$ \\
\hline & $\mathrm{RC212}$ & $0.050 \mathrm{ef}$ & $0.063 \mathrm{def}$ & $* *$ & $0.480 \mathrm{a}$ & $0.693 \mathrm{~cd}$ & ns & $3.210 \mathrm{bcd}$ & $2.750 \mathrm{c}$ & ns \\
\hline \multirow{3}{*}{$\begin{array}{c}\text { Individual } \\
\text { Burgundian }\end{array}$} & A1 & $0.034 \mathrm{bc}$ & $0.055 \mathrm{abc}$ & $* * *$ & $0.332 \mathrm{a}$ & $0.586 \mathrm{bc}$ & $\mathrm{ns}$ & $3.303 \mathrm{bcd}$ & $3.569 \mathrm{~d}$ & $\mathrm{~ns}$ \\
\hline & $\mathbf{A 2}$ & $0.026 \mathrm{a}$ & $0.053 \mathrm{ab}$ & $* *$ & $0.439 \mathrm{a}$ & $0.347 \mathrm{a}$ & ns & $3.362 \mathrm{bcd}$ & $3.336 \mathrm{~d}$ & $\mathrm{~ns}$ \\
\hline & A3 & $0.025 \mathrm{a}$ & $0.052 \mathrm{a}$ & $* * *$ & $0.356 \mathrm{a}$ & $0.847 \mathrm{~d}$ & ns & $3.169 \mathrm{bc}$ & $2.373 \mathrm{~b}$ & ns \\
\hline \multirow{5}{*}{$\begin{array}{c}\text { Mixed } \\
\text { Burgundian }\end{array}$} & M1 (1:1:1) & $0.039 \mathrm{~cd}$ & 0.064 ef & $* * *$ & $0.445 \mathrm{a}$ & $0.726 \mathrm{~cd}$ & ns & $3.294 \mathrm{bcd}$ & $\begin{array}{c}\text { not } \\
\text { quantifiable }\end{array}$ & ns \\
\hline & M2 (1:2:3) & $0.037 \mathrm{~cd}$ & 0.062 cde & $* *$ & $0.415 \mathrm{a}$ & $0.533 \mathrm{abc}$ & $* *$ & $3.780 \mathrm{~cd}$ & $\begin{array}{c}\text { not } \\
\text { quantifiable }\end{array}$ & ns \\
\hline & M3 (3:2:1) & $0.043 \mathrm{de}$ & $0.057 \mathrm{abc}$ & $*$ & $0.342 \mathrm{a}$ & $0.586 \mathrm{bc}$ & $* *$ & $3.909 \mathrm{~d}$ & $4.163 \mathrm{e}$ & ns \\
\hline & M4 (1:3:2) & 0.050 ef & $0.059 \mathrm{abc}$ & ns & $0.383 \mathrm{a}$ & $0.629 \mathrm{bc}$ & $*$ & $3.601 \mathrm{~cd}$ & $3.498 \mathrm{~d}$ & ns \\
\hline & Range & $0.029-0.063$ & $0.052-0.068$ & & $0.332-0.662$ & $0.347-0.864$ & & $1.885-4.677$ & $2.364-4.827$ & \\
\hline
\end{tabular}

a the mean values of the biological replicates of each yeast strain were shown $(n=3){ }^{\mathrm{b}}$ yeast strain means not sharing the same subscript are significantly $(p \leq 0.05)$

different at each temperature. ${ }^{\mathrm{c}} \mathrm{ns},{ }^{*}, * *, * *$ indicates non-significant and significant at $p \leq 0.05,0.01$ and 0.001 , respectively, for temperature effects. 


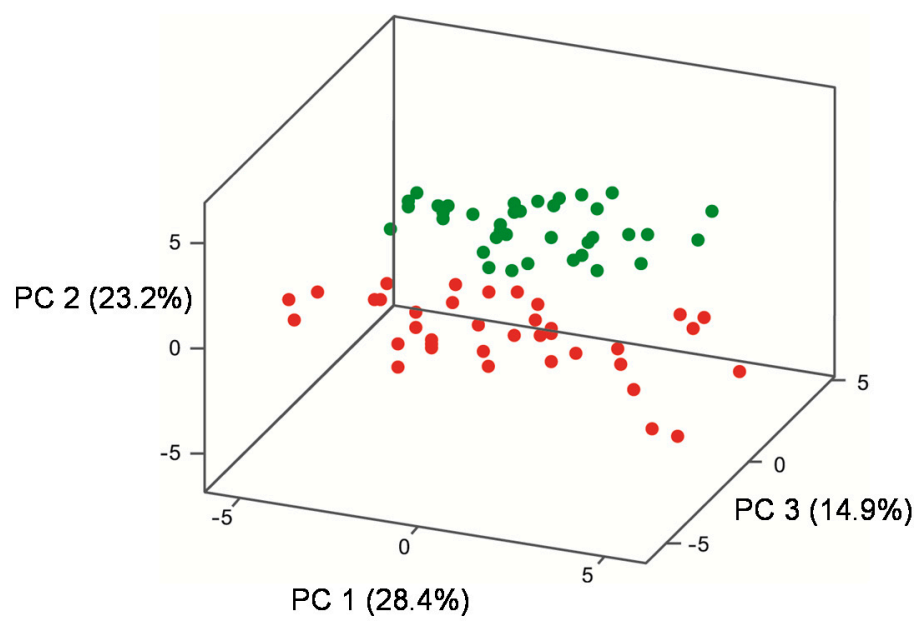

Figure 3. Principal component analysis (PC 1, PC 2, PC 3) of the mean concentration of 25 volatile compounds (nine higher alcohols, seven ethyl esters, five acetate esters, two aldehydes, one acid, one acetal) in Pinot noir, fermented using five industrial strains, three individual- and four mixed-Burgundian $S$. cerevisiae isolates in triplicate, at $22{ }^{\circ} \mathrm{C}$ (green) and $27^{\circ} \mathrm{C}$ (red).

Two of the mixed-Burgundian isolate wines from M1 and M2 were positioned particularly low in the plane (Figure 4a), with extremely high positive PC 1 and negative PC 2 values (Table 5); these wines had very much higher concentration of 1,3-butanediol and 2,3-butandiol (Table 2) and benzaldehyde (Table 4). A separation of the wines by temperature can also be seen in Figure $4 \mathrm{~b}$. Wines fermented at $22{ }^{\circ} \mathrm{C}$ and $27{ }^{\circ} \mathrm{C}$ were grouped diagonally across the plot, primarily located in the under right and lower left, respectively. Those in the upper right $\left({ }^{+} \mathrm{PC} 2,{ }^{+} \mathrm{PC} 3\right.$ ) (Table 5) had higher concentrations of ethyl hexanoate, ethyl butanoate and ethyl octanoate (Table 3), while those in the lower left ( ${ }^{-} \mathrm{PC} 2,{ }^{-} \mathrm{PC} 3$ ) (Table 5) had higher concentrations of 2,3-butanediol and 1,3-butanediol (Table 2), benzaldehyde (Table 4) and acetic acid (Table 4).

Wines on the right hand side were further differentiated along PC 2 , in the upper ( $\left.{ }^{+} \mathrm{PC} 2\right)$ and lower ( ${ }^{-}$PC 2) quadrants. Wines from the industrial stains and the individual- and mixed-Burgundian isolates fermented at $22{ }^{\circ} \mathrm{C}$, were located primarily in quadrant 1 (Figure 4a) with positive PC 1 and PC 2 values (Table 5). These wines had higher concentration of three ethyl esters (ethyl octanoate, ethyl hexanoate, ethyl butanoate) (Table 3). Many of the wines fermented with the individual- and most of the mixed-Burgundian isolates at $27^{\circ} \mathrm{C}$ were located in quadrant 4 (Figure 4a) with positive PC 1 and negative PC 2 values (Table 5). These wines had higher concentrations of three ethyl esters (ethyl laurate, ethyl decanoate, ethyl palmitate) (Table 3), five acetate esters (methyl acetate, ethyl acetate, hexyl acetate, isobutyl acetate, isoamyl acetate) (Table 4), as well as acetaldehyde (Table 4). 

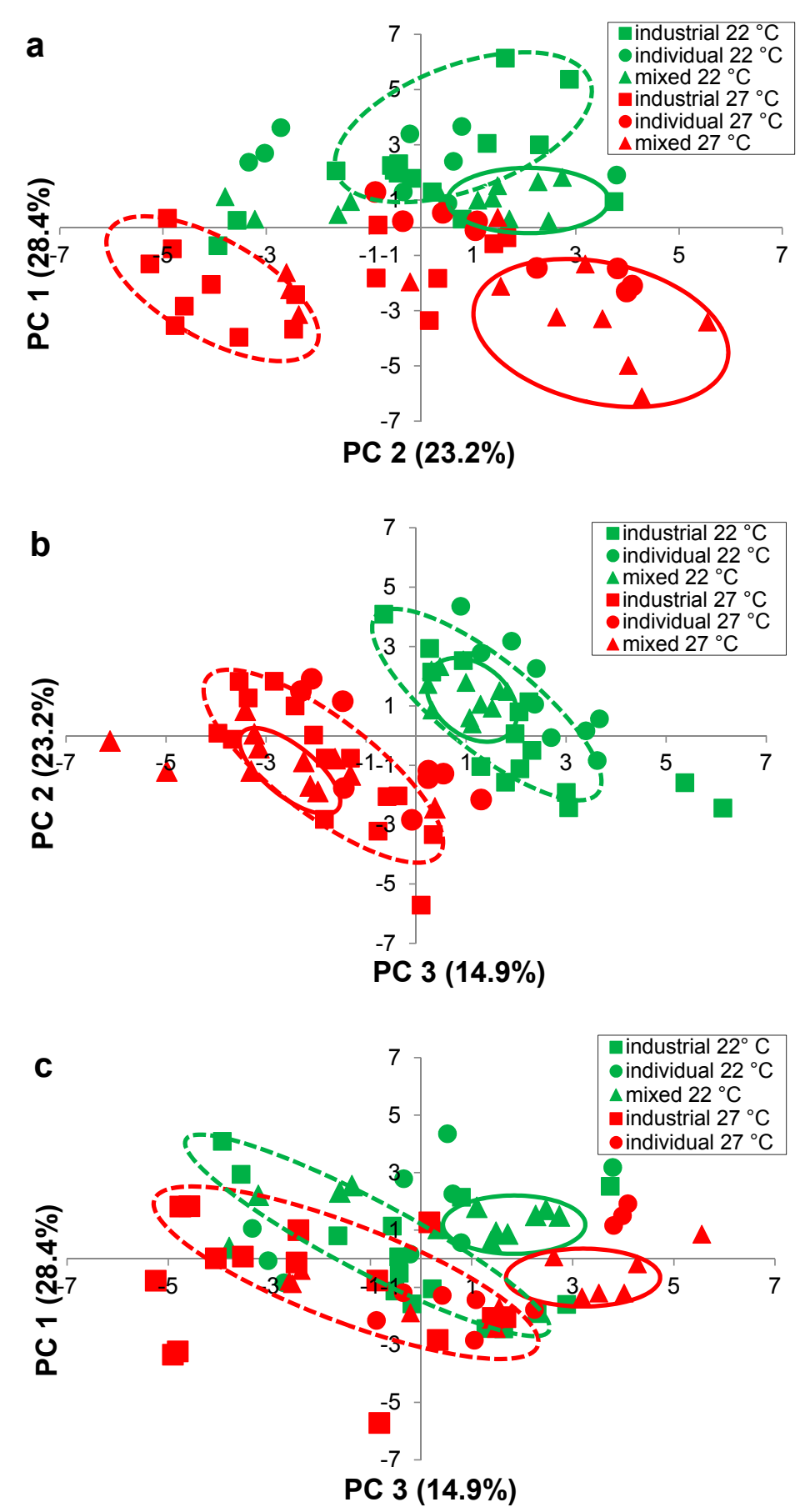

Figure 4. Principal component analysis (PC 1, PC 2, PC 3) of the mean concentration of 25 volatile compounds in Pinot noir, fermented using five industrial yeast strains (squares), three individual-Burgundian (circles) and four mixed-Burgundian (triangles) S. cerevisiae isolates in triplicate, at $22^{\circ} \mathrm{C}$ (green) and $27{ }^{\circ} \mathrm{C}$ (red) (a) plot of $\mathrm{PC} 1$ versus PC 2 (b) plot of PC 1 versus PC 2 and (c) plot of PC 1 versus PC 3. Ellipses drawn around wine fermented with industrial strains (dashed lines) and mixed-Burgundian isolates (solid lines), at $22{ }^{\circ} \mathrm{C}$ (green) and $27^{\circ} \mathrm{C}$ (red), are to aid in discussion only. 
Table 5. Identification and principal component analysis factor loadings (PC 1, PC 2, PC 3) for 25 volatile compounds in the headspace of Pinot noir, fermented with industrial strains and individual- and mixed-Burgundian isolates.

\begin{tabular}{|c|c|c|c|c|c|c|}
\hline $\begin{array}{l}\text { Quadrant in } \\
\text { Figure 4a }\end{array}$ & Volatile Compound & Volatile Class & $\begin{array}{c}\text { Loading a } \\
\text { PC } 1 \text { (x) } \\
28.4 \% \\
\end{array}$ & $\begin{array}{c}\text { Loading a } \\
\text { PC } 2(y) \\
23.2 \% \\
\end{array}$ & $\begin{array}{c}\text { Loading a }^{{ }^{2}} \\
\text { PC } 3(\mathrm{z}) \\
14.9 \% \\
\end{array}$ & $\begin{array}{c}\text { Temperature } \\
\text { that volatile } \\
\text { predominates }\end{array}$ \\
\hline 1 & Propanol & Higher alcohol & 1.10 & 0.20 & 1.02 & Inconclusive \\
\hline 1 & Ethyl octanoate & Ethyl ester & 2.11 & 1.25 & 0.72 & $22^{\circ} \mathrm{C}$ \\
\hline 1 & Ethyl hexanoate & Ethyl ester & 1.76 & 1.44 & 1.29 & $22{ }^{\circ} \mathrm{C}$ \\
\hline 1 & Ethyl butanoate & Ethyl ester & 1.86 & 0.62 & 1.74 & $22{ }^{\circ} \mathrm{C}$ \\
\hline 1 & 1,1-Diethyoxyacetal & Acetal & 0.17 & 0.82 & 0.10 & $22{ }^{\circ} \mathrm{C}$ \\
\hline 3 & 2,3-Butanediol & Higher alcohol & -0.03 & -1.98 & -1.93 & $27^{\circ} \mathrm{C}$ \\
\hline 3 & Isobutanol & Higher alcohol & -0.24 & -1.35 & 1.83 & $27^{\circ} \mathrm{C}$ \\
\hline 3 & Butanol & Higher alcohol & -0.42 & -1.70 & -0.49 & $27^{\circ} \mathrm{C}$ \\
\hline 3 & 3-Methyl-1-butanol & Higher alcohol & -0.88 & -1.69 & 2.38 & $27^{\circ} \mathrm{C}$ \\
\hline 3 & 2-Methyl-1-butanol & Higher alcohol & -1.19 & -1.88 & 1.96 & $27^{\circ} \mathrm{C}$ \\
\hline 3 & Phenylethanol & Higher alcohol & -1.23 & -1.86 & 0.70 & $27^{\circ} \mathrm{C}$ \\
\hline 3 & 1-Hexanol & Higher alcohol & -1.62 & -0.23 & 2.07 & Inconclusive \\
\hline 3 & Ethyl lactate & Ethyl ester & -0.80 & -0.03 & 2.09 & Inconclusive \\
\hline 3 & Benzaldehyde & Aldehyde & -0.03 & -2.22 & -1.09 & $27^{\circ} \mathrm{C}$ \\
\hline 3 & Acetic acid & Acid & -0.14 & -1.88 & -1.08 & $27^{\circ} \mathrm{C}$ \\
\hline 4 & 1,3-Butanediol & Higher alcohol & 0.10 & -2.10 & -1.97 & $27^{\circ} \mathrm{C}$ \\
\hline 4 & Ethyl laurate & Ethyl ester & 1.93 & -1.46 & 0.00 & $27^{\circ} \mathrm{C}$ \\
\hline 4 & Ethyl decanoate & Ethyl ester & 2.35 & -0.43 & -0.41 & $27^{\circ} \mathrm{C}$ \\
\hline 4 & Ethyl palmitate & Ethyl ester & 1.00 & -1.87 & 1.48 & $27^{\circ} \mathrm{C}$ \\
\hline 4 & Methyl acetate & Acetate ester & 1.01 & -0.96 & 2.45 & $27^{\circ} \mathrm{C}$ \\
\hline 4 & Ethyl acetate & Acetate ester & 1.95 & -0.96 & 0.73 & $27^{\circ} \mathrm{C}$ \\
\hline 4 & Hexyl acetate & Acetate ester & 2.45 & -0.02 & -0.51 & Inconclusive \\
\hline 4 & Isobutyl acetate & Acetate ester & 1.36 & -1.89 & 0.42 & $27^{\circ} \mathrm{C}$ \\
\hline 4 & Isoamyl acetate & Acetate ester & 2.31 & -0.95 & -0.07 & $27^{\circ} \mathrm{C}$ \\
\hline 4 & Acetaldehyde & Aldehyde & 1.10 & -0.90 & -1.12 & $27^{\circ} \mathrm{C}$ \\
\hline
\end{tabular}

${ }^{\mathrm{a}}$ coordinates in bold font, with absolute values greater than 1.2 , were most heavily loaded.

The mixed-Burgundian isolates formed smaller tighter subsets within the larger groupings (Figure 4b), suggesting that they were more similar to one another than to the remaining wines. Such findings are consistent with Saberi et al. (2012) [5] who also reported that co-cultured wines were more similar to one another than to industrial strains. The similarity of mixed-Burgundian strain wines was also evident in Figure 4c. Wine fermented with the mixed-Burgundian at $22{ }^{\circ} \mathrm{C}\left({ }^{+} \mathrm{PC} 1,{ }^{+} \mathrm{PC} 3\right.$ ) (Table 5) had higher concentrations of ethyl esters (ethyl octanoate, ethyl hexanoate, ethyl butanoate, ethyl palmitate) (Table 3) and acetate esters (methyl acetate, ethyl acetate) (Table 4). In contrast the mixed-Burgundian wines at $27{ }^{\circ} \mathrm{C}\left({ }^{+} \mathrm{PC} 1,{ }^{-} \mathrm{PC} 3\right)$ (Table 5) had higher concentrations of acetate esters (hexyl acetate, isobutyl acetate and isoamyl acetate) (Table 4) and 1,3-butanediol (Table 2). Close examination of the volatiles produced from the individual-Burgundian isolates (Tables 2-4) revealed that the yeast with the lowest production at $22{ }^{\circ} \mathrm{C}$ was not necessarily the yeasts with the lowest production at $27^{\circ} \mathrm{C}$ (higher alcohols, Table 2; ethyl esters, Table 3; acetate esters/aldedhydes/acid/acetal, Table 4). 
This suggested that the strain differences, while significant, may be subtle compared to the magnitude of the temperature differences. For example, the low concentration of 3-methyl-1-butanol in the co-cultured wine $\mathrm{M} 2$ at $22{ }^{\circ} \mathrm{C}\left(10.49 \mathrm{mg} \cdot \mathrm{L}^{-1}\right.$, Table 2) reflected the concentration associated with the low producer A3 (9.921 $\mathrm{mg} \cdot \mathrm{L}^{-1}$, Table 2). Similarly, the low concentrations of ethyl butanoate (2.826 $\mathrm{mg} \cdot \mathrm{L}^{-1}$, Table 3) and ethyl acetate $\left(0.00104 \mathrm{mg} \cdot \mathrm{L}^{-1}\right.$, Table 4) in $\mathrm{M} 4$ at $22{ }^{\circ} \mathrm{C}$ were consistent with the concentrations produced by the dominant yeast A2 (ethyl butanoate, $2.286 \mathrm{mg} \cdot \mathrm{L}^{-1}$, Table 3; ethyl acetate $0.00096 \mathrm{mg} \cdot \mathrm{L}^{-1}$, Table 4). Such results were consistent with the inoculation and fermentation ratios (Figure 2) and are a testament to the fact that co-cultured yeasts can be used to significantly modify the headspace volatiles of a wine. Such trends were not as readily apparent at $27^{\circ} \mathrm{C}$, in part due to the fact that the inoculation ratios were not as well maintained at this temperature.

The volatile compositions of the wine from the mixed-Burgundian isolates were unattainable by any single industrial yeast strain. Although the compound 2,3-butanediol may be present at relatively high concentrations (Table 2) [25], its contribution to wine aroma is somewhat elusive given its high detection threshold $\left(150 \mathrm{mg} \cdot \mathrm{L}^{-1}\right)$ [26]. Similarly, propanol's contribution to wine aroma is unclear [27]. However, it shows an inverse correlation with hydrogen sulfide [28], suggesting that wines from mixed-Burgundian isolates may have a lower propensity to sulfur flaws.

While the higher alcohols (1-hexanol, 3-methyl-1-butanol, 2-methyl-1-butanol) can contribute to wine quality at low concentrations $\left(\sim 300 \mathrm{mg} \cdot \mathrm{L}^{-1}\right)$, they can detract from wine quality at high concentrations $\left(\sim 400 \mathrm{mg} \cdot \mathrm{L}^{-1}\right)$ [29]. In the context of this study, it is difficult to determine whether the increased in concentration of these higher alcohols for the mixed-Burgundian isolates represents a positive, negative, or negligible impact on the sensory properties of the wine. Nevertheless, the differences in higher alcohol production and the unique combination of higher alcohols in wines fermented with mixed-Burgundian yeasts could indicate the future potential of mixed strain yeast products.

The industrial strains and mixed-Burgundian isolates at $27^{\circ} \mathrm{C}$ had a propensity to produce slightly more ethyl esters during fermentation (Table 3). Esters are particularly important to wine aroma for they can be perceived sensorially. Although Ferreira et al. [30] suggests that acetate and ethyl esters may only play a modulatory role in red wine aroma, their contribution would be expected to be dependent on the style of red wine, particularly if the Pinot noir was prepared without skin contact as in this research Howell et al. [17] identified that co-culturing wines produced volatile profiles that could not be replicated by fermenting each strain individually, or by blending the wines from single cultures. This suggests that co-cultured yeasts may be sharing metabolites [31] and creating unique volatile profiles that are more than the sum of their parts. King et al. [16] reported that consumers, who were familiar with the higher priced wines, preferred wines that had been co-cultured with two yeast strains. Such findings are consistent with Saberi et al. [5] and Grossman et al. [32] who report that co-cultured wines had intermediate concentrations of odor active compounds and were perceived as more complex, respectively. As such the isolates evaluated in this research offer winemakers an opportunity to produce wines with unique and/or more complex characters. 


\section{Experimental Section}

\subsection{Yeast and Bacterial Strains Employed}

Three novel S. cerevisiae strains (A1, A2, A3) were isolated in 2007 from a vineyard in Burgundy France and preserved in $15 \%$ glycerol/yeast peptone dextrose (YPD) broth at $-80{ }^{\circ} \mathrm{C}$. These isolates were compared to five commercially available $S$. cerevisiae strains, which were recommended for Pinot noir fermentation. The industrial strains Enoferm Assmanshausen (AMH), Enoferm Burgundy (BGY), Lalvin RA17 (RA17) and Lalvin Bourgorouge RC212 (RC212) were purchased as active dry yeast from Lallemand Inc. (Rexdale, ON, Canada); whereas Australian Wine Research Institute 796 (AWRI796) was obtained as an agar slant from Mauri Yeast Australia (Sydney, Australia).Yeast for the killer phenotyping assay, S. cerevisiae wine strains EC 1118 and UCD 522 (Montrachet), were obtained from freezer stocks maintained by the van Vuuren laboratory. The malolactic O. oeni bacterial strain Lalvin 31 was purchased from Lallemand Inc. The individual-Burgundian isolates were prepared in four mixtures (M1, M2, M3, M4) consisting of the ratios of the isolates A1, A2 and A3 as follows: $1: 1: 1,1: 2: 3,3: 2: 1$ and 1:3:2, respectively.

\subsection{Media and Culture Conditions}

All S. cerevisiae strains were maintained as freezer stocks at $-80{ }^{\circ} \mathrm{C}$ in $15 \%$ glycerol/YPD and cultured in Difco YPD broth and agar (Becton, Dickinson and Co., Franklin Lakes, NJ, USA) according to standard procedures [33]. Lyophilized $O$. oeni was rehydrated in $50 \mathrm{~mL}$ of sterile distilled water for $15 \mathrm{~min}$ and used directly for the malolactic fermentation compatibility study.

Killer assay medium was formulated by buffering YPD agar with $50 \mathrm{mM}$ dibasic phosphate and adjusting the $\mathrm{pH}$ to 4.2 with citric acid prior to autoclaving. Filter sterile $(0.22 \mu \mathrm{m})$ methylene blue was added at a rate of $0.0015 \% \mathrm{w} / \mathrm{v}$ (adapted from van Vuuren and Wingfield [34]).

Free run Pinot noir and Chardonnay grape must (2008) were obtained from Calona Vineyards (Kelowna, BC, Canada). It had been crushed, pressed and treated with $\sim 50 \mathrm{mg} \mathrm{kg}^{-1}$ sulfur dioxide, then frozen prior to shipment to the Wine Research Centre (Vancouver, BC, Canada). Pinot noir must was thawed just prior to inoculation; its composition was: $25.2^{\circ} \mathrm{Brix}, 3.77 \mathrm{pH}, 5.62 \mathrm{~g} \cdot \mathrm{L}^{-1}$ titratable acidity (TA) and $244 \mathrm{mg} \cdot \mathrm{L}^{-1}$ yeast available nitrogen (YAN). Chardonnay juice was used for the growth kinetic and phenotyping assays, since a lightly colored juice was required for the spectrophotometric determinations. Chardonnay juice was sterilized using a $0.22 \mu \mathrm{m}$ filter; its composition was: $27.0^{\circ}$ Brix, $3.46 \mathrm{pH}, 5.76 \mathrm{~g} \cdot \mathrm{L}^{-1} \mathrm{TA}$ and $121 \mathrm{mg} \cdot \mathrm{L}^{-1} \mathrm{YAN}$.

\subsection{Genetic Fingerprinting and Monitoring of Mixed Strains During Fermentation}

S. cerevisiae strains were genetically fingerprinted with the PCR method and the primers $\delta 12$ and $\delta 2$ described in Schuller et al. [18]. S. cerevisiae strains were grown and genomic DNA was extracted [33]. A $50 \mu \mathrm{L}$ reaction mixture was prepared, which contained $10 \mathrm{ng}$ of DNA template, $1 \mathrm{U}$ iProof DNA polymerase (BioRad, Mississauga, ON, Canada), $5 \times$ GC buffer, 0.5\% v/v DMSO, $0.2 \mathrm{mM}$ of each $\mathrm{dNTP}$, and $25 \mathrm{pmol}$ of each primer. After the initial denaturation at $98{ }^{\circ} \mathrm{C}$ for 3 minutes, the reaction mixture was cycled 30 times according to the following program: $98{ }^{\circ} \mathrm{C}$ for $10 \mathrm{~s}, 55^{\circ} \mathrm{C}$ for $1 \mathrm{~min}$, and 
$72{ }^{\circ} \mathrm{C}$ for $1 \mathrm{~min}$, which was followed by a final elongation period at $72{ }^{\circ} \mathrm{C}$ for $10 \mathrm{~min}$. The PCR products were separated by gel electrophoresis on a 1.5\% agarose gel and visualized with SYBR Safe DNA gel stain (Invitrogen Inc., Burlington, ON, Canada).

Wine fermentations containing the Burgundian isolates (A1, A2, A3) in the mixtures M1 (1:1:1), M2 (1:2:3), M3 (3:2:1), and M4 (1:3:2) were monitored with genetic fingerprinting of the individual visualized through colony PCR. Cells were harvested by centrifugation $(5000 \times g$ for $5 \mathrm{~min})$ at the midpoint $(9 \% \mathrm{v} / \mathrm{v}$ ethanol) and end $(13.5 \% \mathrm{v} / \mathrm{v}$ ethanol) of fermentation. Cells were resuspended and diluted in sterile MilliQ water before being grown up on YPD agar plates at $30^{\circ} \mathrm{C}$ for $3 \mathrm{~d}$. The genetic fingerprints of 45 colonies from each replicate $(n=3)$ at each time point $(n=2)$ and temperature $(n=2)$ were assessed via colony PCR by substituting a small amount of colony for the DNA template in the method described above and increasing the initial denaturation period to 10 minutes.

\subsection{Killer Factor Phenotyping}

The killer factor phenotype was assessed in the individual-Burgundian isolates (A1, A2, A3) against the killer positive control $\left(\mathrm{K}^{+}\right) S$. cerevisiae strain EC1118, and killer negative control $\left(\mathrm{K}^{-}\right)$S. cerevisiae strain UCD522. All strains were grown on YPD-agar plates for $72 \mathrm{~h}$ at $30{ }^{\circ} \mathrm{C}$. Three colonies of sensitive strain $\mathrm{AMH}$ were picked and resuspended in sterile MilliQ water to give $5 \times 10^{8} \mathrm{cells}^{-1}$; $300 \mu \mathrm{L}$ of this suspension was spread as a lawn on a plate containing killer assay medium and allowed to dry. Colonies from each of the other strains were swabbed and spread as a thick line on top of the killer lawn. The plate was then incubated at $18^{\circ} \mathrm{C}$ for $5 \mathrm{~d}$ (adapted from van Vuuren and Wingfield [34].

\subsection{Model Fermentations-Fermentation Characteristics}

S. cerevisiae freezer stocks were used to inoculate $5 \mathrm{~mL}$ cultures of YPD, which were grown overnight in a rotary wheel to stationary phase at $30{ }^{\circ} \mathrm{C}$. Flasks containing $50 \mathrm{~mL}$ of YPD were subsequently inoculated at a rate of $5 \times 10^{5}$ cells $\mathrm{mL}^{-1}$ and grown aerobically in a shaker bath (180 rpm) for $24 \mathrm{~h}$ at $30^{\circ} \mathrm{C}$. Cells were harvested by centrifugation $(5000 \times \mathrm{g}$ for $5 \mathrm{~min})$, washed with sterile MilliQ water, and resuspended in fermentation medium at a density of $5 \times 10^{8}$ cells $\mathrm{mL}^{-1}$. Fermentations were inoculated in biological triplicate at a rate of $2 \times 10^{6}$ cells mL $\mathrm{m}^{-1}$. In the case of the mixed strain fermentations, yeast strains were not combined prior to inoculation of the fermentation medium. All fermentations were conducted in media bottles topped with rubber bungs and water-filled capped gas locks to ensure anaerobic conditions. Sampling occurred anaerobically by piercing the rubber bungs with 5-inch hypodermic needles (Air-Tite Products Co., Virginia Beach, VA, USA) attached to $3 \mathrm{~mL}$ syringes (Becton, Dickinson and Co., Franklin Lakes, NJ, USA) and extracting approximately $1 \mathrm{~mL}$ of sample.

The primary experimental fermentations were conducted in triplicate in $900 \mathrm{~mL}$ of Pinot noir must at $22{ }^{\circ} \mathrm{C}$ and $27^{\circ} \mathrm{C}$, respectively, and were used to assess fermentation kinetics, ethanol, glycerol, and acetic acid production, mixed strain population dynamics, and production of volatile compounds. Sampling occurred twice daily early in the early stage, daily in the intermediate stage, and every two days in the final stage of fermentation. Ethanol production, form formation and glycerol production were measured at each time while acetic acid and the volatile compounds were assessed at the end of fermentation. Fermentation samples were vortexed, centrifuged, and filter sterilized $(0.22 \mu \mathrm{m})$ before 
compounds were analysed. After sugars were depleted, $100 \mathrm{mg} \cdot \mathrm{L}^{-1}$ of potassium metabisulfite was added to the wine to protect against oxidation. Samples were stored at $4{ }^{\circ} \mathrm{C}$ until GC-MS analysis. The ethanol tolerance of the various $S$. cerevisiae strains was assessed by fermenting each strain in biological triplicate in a high sugar must. This must was created by supplementing the Pinot noir must to $33 \%$ sugar, using equi-molar amounts of glucose and fructose (Fisher Scientific, Ottawa, ON, Canada). Fermentations were sampled initially and after the fermentations were complete $(21 \mathrm{~d})$ and the concentration of ethanol determined and expressed in $\% \mathrm{v} / \mathrm{v}$, as described above.

Sulfur dioxide production by yeasts was assayed following the alcoholic fermentation in biological triplicate in $200 \mathrm{~mL}$ of synthetic juice at $22{ }^{\circ} \mathrm{C}$ and $27^{\circ} \mathrm{C}$. Sulfur dioxide was quantified in technical triplicate according to manufacturer protocols using the "Total $\mathrm{SO}_{2}$ " UV test kit from R-Biopharm (Darmstadt, Germany). Unfermented synthetic juice was also assayed to ensure that it was free from sulfite contamination.

The malolactic compatibility of the strains was assessed following the alcoholic fermentation in biological triplicate in $400 \mathrm{~mL}$ of Pinot noir must at $22^{\circ} \mathrm{C}$. Wines were inoculated with $O$. oeni strain MBR 31 and fermented at $20^{\circ} \mathrm{C}$. Samples were collected and analysed for malic and lactic acids at 3-4 d intervals for $18 \mathrm{~d}$.

\subsection{Growth Phenotype Assay}

The growth phenotypes of the yeasts were assayed in a Bioscreen $\mathrm{C}$ Growth Chamber (Thermo-Labsystems) in filter sterilized $(0.22 \mu \mathrm{m})$ Chardonnay juice (Calona Vineyards). The S. cerevisiae strains were grown to stationary phase in $5 \mathrm{~mL}$ cultures of YPD at $30{ }^{\circ} \mathrm{C}$ in a rotary wheel, harvested by centrifugation $(5000 \times g$ for $5 \mathrm{~min})$ and resuspended in Chardonnay juice. The juice was then inoculated at a rate of $5 \times 10^{5}$ cells $\mathrm{mL}^{-1}$ and $150 \mu \mathrm{L}$ aliquots were transferred in triplicate into a 100-well Bioscreen $\mathrm{C}$ optical plate (Thermo-Labsystems). The optical plate was placed in the growth chamber and grown for $96 \mathrm{~h}$ with continuous shaking at $22{ }^{\circ} \mathrm{C}$ and $27{ }^{\circ} \mathrm{C}$. The OD (A600nm) was measured automatically each hour; data were compiled using the affiliated Biolink-DOS software.

\subsection{Foam Production Assay}

Foam production was assessed in yeasts at $22{ }^{\circ} \mathrm{C}$ and $27{ }^{\circ} \mathrm{C}$ using an assay modified from Regodón et al. [35]. Yeasts were cultured in preparation for fermentation and were inoculated into $18 \times 150 \mathrm{~mm}$ test tubes containing $10 \mathrm{~mL}$ of Pinot noir juice. Foam height was monitored three times per day and the maximum height achieved was measured and recorded in millimeters.

\subsection{Quantification of Compounds Using HPLC}

Ethanol, glycerol and acetic acid were quantified according with an Agilent 1100 series HPLC (Agilent Technologies, Palo Alto, CA, USA) using a Supelcogel C-61OH $30 \mathrm{~cm} \times 7.8 \mathrm{~mm}$ column (Sigma-Aldrich, Oakville, ON, Canada), an Agilent G1362A refractive index detector with positive polarity and Agilent LC-MS ChemStation revision A.09.03 software. The method consisted of a $23 \mathrm{~min}$ isocratic run of $0.1 \%$ phosphoric acid at $0.75 \mathrm{~mL} \mathrm{~min}^{-1}$ [36]. Peak monitoring was performed with an Agilent G1362A refractive index detector (Agilent, Santa Clara, CA, USA). Concentrations were 
determined for each of the three replicates from the standard curves. Glycerol and acetic acid concentrations were reported in $g \cdot \mathrm{L}^{-1}$. Ethanol concentrations were reported in percentage $(\mathrm{v} / \mathrm{v})$, in order to be consistent with units utilized by the wine industry.

\subsection{Identification and Quantification of Volatile Compounds Using GC-MS}

GC-MS headspace analysis was used to analyze Pinot noir wine samples according to the method of Danzer et al. [37], without solid phase microextraction (SPME) as described in Husnik et al. [1]. An Agilent $6890 \mathrm{~N}$ GC interfaced to a 5973N Mass Selective Detector along with a $60 \mathrm{~m} \times 0.25 \mathrm{~mm}$ ID, $0.25 \mu \mathrm{m}$ thickness DBWAX fused silica open tubular column (J\&W Scientific, Folsom, CA, USA) were used to detect and quantify volatile compounds, which were analysed with Enhanced Chemstation software (MSD Chemstation Build 75, Agilent Technologies, Palo Alto, CA, USA) and identified with the Wiley7Nist05 library (Wiley and Sons, Hoboken, NJ, USA).

\subsection{Statistical Analyses}

One-factor ANOVA with replication were used to examine the ethanol, glycerol, acetic acid, sulfur dioxide and volatile effects among the yeast strains using MS Excel 2010 (Microsoft, Redmond, WA, USA). Differences among strains were differentiated using Fisher's least significant difference (LSD) at $p \leq 0.05$ and delineated using subscripts.

Principal component analysis (PCA) was used to examine the patterns of 25 volatile compounds associated with the wine products from the five industrial strains and three individual- and four mixed-Burgundian isolates, at both fermentation temperatures in triplicate using Minitab 16 (Minitab Inc., State College, PA, USA). Vector coordinates were scaled by a factor of five times to aid in visualization of the data. A principal component (PC) plot was prepared for the first three dimensions (3d-plot) in Minitab 16 (Minitab Inc., State College, PA, USA). Two dimensional figures (2-d plots) of PC 1 versus PC 2, PC 2 versus PC 3 and PC 1 versus PC 3 were prepared in MS Excel (Microsoft, Redmond, WA, USA). Ellipses were drawn on these plots around the industrial strains and mixed-Burgundian isolates as visual aids only.

\section{Conclusions}

This research demonstrated the three Burgundian $S$. cerevisiae isolates (A1, A2, A3) were genetically unique from five industrial strains (AMH, AWRI796, BGY, RA17, RC212), killer positive and compatible with malolactic bacteria. The individual- and mixed-cultures of these new isolates were demonstrated to be suitable for winemaking, since their enological characteristics fell within the range associated with the industrial strains.

ANOVA of the 25 volatile compounds (nine alcohols, seven ethyl esters, five acetate esters, two aldehydes, one acid, one acetal) revealed differed among the yeast strains. Principal component analysis revealed that the differences in the volatile profiles among the yeasts (industrial, individualand mixed-Burgundian) were more subtle than those due to temperature. Mixed-Burgundian isolates at $22{ }^{\circ} \mathrm{C}$ and $27{ }^{\circ} \mathrm{C}$ produced lower concentrations of higher alcohols than industrial yeasts at $27{ }^{\circ} \mathrm{C}$, creating wines with unique volatile profiles. In general, the mixed-Burgundian strain wines were more 
similar to one another than to the industrial strains, with higher concentrations of several ethyl ester and acetate esters. This research documented that co-culturing novel strains can produce wines with unique volatile profiles, without the risks of spontaneous fermentation. As such, a commercial multi-yeast starter culture could serve as a winemaking tool to increase wine complexity and improve wine differentiation in the marketplace. However, much research remains to be conducted to optimize performance of the co-cultured strains, understand the mechanisms of yeast-yeast interaction, evaluate the relative contribution of the strains to overall wine flavor, elucidate the volatile/non-volatile interactions, and understand the changes to volatiles during ingestion and consumption.

\section{Acknowledgments}

The authors would like to acknowledge Lina Madilao for the GC-MS headspace analyses. This research was funded by an NSERC Discovery Grant 217271-09 to H.J.J. van Vuuren.

\section{Author Contributions}

Emily Terrell: experimental work, data analyses and manuscript preparation. Margaret Cliff: statistical analyses and manuscript preparation: Hennie J.J. van Vuuren: conceptualization, experimental work, data analyses and manuscript preparation.

\section{Conflicts of Interest}

The authors declare no conflict of interest.

\section{References}

1. Husnik, J.; Delaquis, P.A.; Cliff, M.A.; van Vuuren, H.J.J. Functional analysis of the malolactic wine yeast ML01. Am. J. Enol. Vitic. 2007, 58, 42-52.

2. Clemente-Jimenez, J.M.; Mingorance-Cazorla, L.; Martínez-Rodríguez, S.; Las Heras-Vázquez, F.J.; Rodríguez-Vico, F. Influence of sequential yeast mixtures on wine fermentation. Int. J. Food Microbiol. 2005, 98, 301-308.

3. Rojas, V.; Gil, J.V.; Piñaga, F.; Manzanares, P. Acetate ester formation in wine by mixed cultures in laboratory fermentations. Int. J. Food Microbiol. 2003, 86, 181-188.

4. King, E.S.; Swiegers, J.H.; Travis, B.; Francis, I.L.; Bastian, S.E.P.; Pretorius, I.S. Coinoculated fermentations using Saccharomyces yeasts affect the volatile composition and sensory properties of Vitis vinifera L. cv. Sauvignon blanc wines. J. Agric. Food Chem. 2008, 56, 10829-10837.

5. Saberi, S.; Cliff, M.A.; van Vuuren, H.J.J. Impact of mixed S. cerevisiae strains on the production of volatiles and estimated sensory profiles of Chardonnay wines. Food Res. Internat. 2012, 48, $725-735$.

6. Carrau, F.; Gaggero, C.; Aguilar, P.S. Yeast diversity and native vigor for flavor phenotypes. Trends Biotechnol. 2015, 33, 148-154.

7. Zambonelli, C. Microbiologia e Biotecnologia dei Vini; Edagricole: Bologna, Italy, 1998.

8. Pretorius, I.S. Tailoring wine yeast for the new millennium: Novel approaches to the ancient art of winemaking. Yeast 2000, 16, 675-729. 
9. Lambrechts, M.G.; Pretorius, I.S. Yeast and its importance to wine aroma-A review. S. Afr. J. Enol. Vitic. 2000, 21, 97-129.

10. Moio, L.; Etievant, P.X. Ethyl anthranilate, ethyl cinnamate, 2,3-dihydrocinnamate, and methyl anthranilate: Four important odorants identified in Pinot noir wines of Burgundy. Am. J. Enol. Vitic. 1995, 46, 392-398.

11. Aubry, V.; Etievant, P.X.; Ginies, C.; Henry, R. Quantitative determination of potent flavor compounds in Burgundy Pinot noir wines using a stable isotope dilution assay. J. Agric. Food Chem. 1997, 45, 2120-2123.

12. Etievant, P.; Issanchou, S.; Bayonove, C.L. The flavor of Muscat wine: The sensory contribution of some volatile compounds. J. Sci. Food Agric. 1983, 34, 497-504.

13. Fang, Y.; Qian, M.C. Quantification of Selected Aroma-Active Compounds in Pinot noir Wines from Different Grape Maturities. J. Agric. Food Chem. 2006, 22, 8567-8573.

14. Styger, G.; Prior, B.; Bauer, F.F. Wine flavor and aroma. Ind. Microbiol. Biotechnol. 2011, 38, $1145-1159$.

15. Jolly, N.P.; Augustyn, O.P.H.; Pretorius, I.S. The role and use of non-Saccharomyces yeasts in wine production. S. Afr. J. Enol. Vitic. 2006, 27, 15-39.

16. King, E.S.; Kievit, R.L.; Curtin, C.; Swiegers, J.H.; Pretorius, I.S.; Bastian, S.E.P.; Francis, I.L. The effect of multiple yeasts co-inoculations on Sauvignon Blanc wine aroma composition, sensory properties and consumer preference. Food Chem. 2010, 122, 618-626.

17. Howell, K.S.; Cozzolino, D.; Bartowsky, E.J.; Fleet, G.H.; Henschke, P.A. Metabolic profiling as a tool for revealing Saccharomyces interactions during wine fermentation. FEMS Yeast Res. 2006, 6, 91-101.

18. Schuller, D.; Valero, E.; Dequin, S.; Casal, M. Survey of molecular methods for the typing of wine yeast strains. FEMS Microbiol. Lett. 2004, 231, 19-26.

19. Ranieri, S.; Pretorius, I.S.; Selection and improvement of wine yeasts. Ann. Microbiol. 2000, 50, $15-31$.

20. Van Vuuren, H.J.J.; Jacobs, C.J. Killer yeasts in the wine industry: A review. Am. J. Enol. Vitic. 1992, 43, 119-128.

21. Saberi, S.; Cliff, M.A.; van Vuuren, H.J.J. Comparison of genetic and enological characteristics of new and existing S. cerevisiae strains for Chardonnay wine fermentations. Food Biotechnol. 2014, $28,195-215$.

22. Remize, F.; Roustan, J.L.; Sablayrolles, J.M.; Barre, P.; Dequin, S. Glycerol overproduction by engineered Saccharomyces cerevisiae wine yeast strains leads to substantial changes in by-product formation and to a stimulation of fermentation rate in stationary phase. Appl. Environ. Microbiol. 1999, 65, 143-149.

23. Eglinton, J.; Henschke, P.A. The occurrence of volatile acidity in Australian wines. Aust. Grapegr. Winemaker. 1999, 426a, 7-12.

24. Arriagada-Carrazanaa, J.P.; Sáez-Navarretea, C.; Bordeu, E. Membrane filtration effects on aromatic and phenolic quality of Cabernet Sauvignon wines. J. Food Eng. 2005, 68, 363-368.

25. Romano, P. Metabolic characteristics of wine strains during spontaneous and inoculated fermentation. Food Technol. Biotechnol. 1997, 35, 255-260.

26. Dubois, P. Les arômes des vins et leurs défauts. Revue Francaise d'œnologie 1994, 145, $27-40$. 
27. Rankine, B.C. Formation of higher alcohols by wine yeasts, and relationship to taste threshold. J. Sci. Food Agric. 1967, 18, 583-589.

28. Giudici, P.; Zambonelli, C.; Kunkee, R.E. Increased production of n-propanol in wine by yeast strains having an impaired ability to form hydrogen sulfide. Am. J. Enol. Vitic. 1993, 44, 17-21.

29. Clarke, R.J.; Bakker, J. Wine Flavor Chemistry; Blackwell Publishing: Oxford, UK, 2004.

30. Ferreira, V.; Fernández, P.; Peña, C.; Escudero, A.; Cacho, J.F. Investigation on the role played by fermentation esters in the aroma of young Spanish wines by multivariate analysis. J. Sci. Food Agric. 1995, 67, 381-392.

31. Cheraiti, N.; Guezenec, S.; Salmon, J.M. Redox interactions between Saccharomyces cerevisiae and Saccharomyces uvarum in mixed culture under enological conditions. Appl. Environ. Microbiol. 2005, 71, 255-260.

32. Grossman, M.; Linsemeyer, H.; Muno, H.; Rapp, A. Use of oligo-strain yeast cultures to increase complexity of wine aroma. Vitic. Enol. Sci. 1996, 51, 175-179.

33. Ausubel, F.M.; Brent, R.; Kingston, R.E.; Moore, D.D.; Seidman, J.G.; Smith, J.A.; Struhl, K. Short Protocols in Molecular Biology; Wiley \& Sons: New York, NY, USA, 1999.

34. Van Vuuren, H.J.J.; Wingfield, B.D. Killer yeasts-The cause of stuck fermentations in a wine cellar. S. Afr. J. Enol. Vitic. 1986, 7, 113-118.

35. Regodón, J.A.; Peréz, F.; Valdés, M.E.; de Miguel, C.; Ramírez, M. A simple and effective procedure for selection of wine yeast strains. Food Microbiol. 1997, 14, 247-254.

36. Adams, C.; van Vuuren, H.J.J. The timing of diammonium phosphate addition to fermenting grape must affects the production of ethyl carbamate in wine. Am. J. Enol. Vitic. 2010, 61, 125-129.

37. Danzer, K.; Garcia, D.D.; Thiel, G.; Reichenbacher, M. Classification of wine samples according to origin and grape varieties on the basis of inorganic and organic trace analyses. Am. Lab. 1999, $31,26-34$.

Sample Availability: Not available.

(C) 2015 by the authors; licensee MDPI, Basel, Switzerland. This article is an open access article distributed under the terms and conditions of the Creative Commons Attribution license (http://creativecommons.org/licenses/by/4.0/). 